The University of Southern Mississippi The Aquila Digital Community

Doctoral Projects

Fall 12-2012

\title{
Exploration of Self-Care Following Distribution of Acute Management Tool for Elder Heart Failure Patients in Clinic Setting
}

Sharon Elaine Vincent

University of Southern Mississippi

Follow this and additional works at: https://aquila.usm.edu/dnp_capstone

Part of the Nursing Administration Commons, and the Public Health and Community Nursing Commons

\section{Recommended Citation}

Vincent, Sharon Elaine, "Exploration of Self-Care Following Distribution of Acute Management Tool for Elder Heart Failure Patients in Clinic Setting" (2012). Doctoral Projects. 37.

https://aquila.usm.edu/dnp_capstone/37

This Doctoral Nursing Capstone Project is brought to you for free and open access by The Aquila Digital Community. It has been accepted for inclusion in Doctoral Projects by an authorized administrator of The Aquila Digital Community. For more information, please contact Joshua.Cromwell@usm.edu. 
The University of Southern Mississippi

EXPLORATION OF SELF-CARE FOLLOWING DISTRIBUTION OF

ACUTE MANAGEMENT TOOL FOR ELDER HEART

FAILURE PATIENTS IN CLINIC SETTING

\author{
by \\ Sharon Elaine Vincent

\begin{abstract}
Capstone Project
Submitted to the Graduate School

of The University of Southern Mississippi

in Partial Fulfillment of the Requirements

for the Degree of Doctorate of Nursing Practice
\end{abstract}

December 2012 


\title{
ABSTRACT \\ EXPLORATION OF SELF-CARE FOLLOWING DISTRIBUTION OF \\ ACUTE MANAGEMENT TOOL FOR ELDER HEART
}

FAILURE PATIENTS IN CLINIC SETTING

\author{
by Sharon Elaine Vincent
}

December 2012

The aim of this study was to develop a broad understanding of heart failure patients' perceptions about their lived experiences. An acute symptom management tool, Red Flags I Need to Know: Heart Failure Action Plan (Health Net Federal Services, 2011), was distributed to the patients prior to initiation of the project. The problem of heart failure rehospitalization is significant. Cost of treatment for heart disease in the United States exceeds all other conditions. The national excessive 30 -day readmission rate in elders post-discharge is $24.8 \%$. Pay-forperformance initiatives will reduce reimbursement for excessive readmissions beginning FY 2013.

The project was a mixed method, qualitative, and quantitative study. Psychometric quality-of-life outcome measures from the Patient Care Outcome Scale (POS) provided empirical data. An ANOVA analysis determined differences between patients, caregivers, and staff in outcome measures. Glaser and Strauss's (2009) grounded theory guided the qualitative analysis of elder HF patients $(N=10)$ in a clinic setting. The transactional model of stress and adaptation (Lazarus, DeLongis, Folkman, \& Gruen, 1985) gave meaning to patient adherence.

Quantitative comparisons of patient, staff, and caregiver scores were not 
significantly different; patients and caregivers did not check overwhelming symptoms. However, when only patient and staff responses were compared, patients reported experiencing significantly higher scores of severe symptoms than staff, $F(1,9)=6.644, p=.03$. Patient scores of three individual questions were significantly higher than staff. This result suggested staff was not recognizing all symptoms patients experienced. Several main themes that emerged from qualitative findings were extreme fatigue, anxiety, and fragmented healthcare systems.

Staff was not recognizing all the pain and other symptoms experienced by patients in this sample. Limitations were small sample size and all patients did not have caregivers. It is recommended that the study be replicated with (a) a larger sample of more diverse participants, (b) all participants do in fact have caregivers, and (c) the project be conducted over a longer period of time. It is also recommended that care and watchfulness will be practiced when assessing patient symptoms in the future.

Dissemination of the acute management tool is recommended for all HF patients at discharge transition. 
COPYRIGHT BY

SHARON ELAINE VINCENT

2012 
The University of Southern Mississippi

\title{
EXPLORATION OF SELF-CARE FOLLOWING DISTRIBUTION OF \\ ACUTE MANAGEMENT TOOL FOR ELDER HEART \\ FAILURE PATIENTS IN CLINIC SETTING
}

\author{
by \\ Sharon Elaine Vincent \\ A Capstone Project \\ Submitted to the Graduate School \\ of The University of Southern Mississippi \\ in Partial Fulfillment of the Requirements \\ for the Degree of Doctorate of Nursing Practice
}

Approved:

Director

Dean of the Graduate School

December 2012 


\section{ACKNOWLEDGMENTS}

The author wishes to express thanks to her husband, son, and daughter for their relentless encouragement during the course of the Capstone Project. The author thanks committee members, Chair Dr. Kathleen Masters, member Dr. Janie Butts, and consultant Dr. Karen Mutsch, for discussion and communication during the course of the Capstone. Appreciation is also given to Dr. J. T. Johnson, research consultant at The University of Southern Mississippi, for statistical analyses. Thanks are expressed also to Dr. Karen Lundy, PhD, RN, FAAN, expert qualitative reviewer, for her contributions.

The project could not have taken place without the input of and collaboration with champion Brad Massey, ACNP and CEO of Pioneerhealth LLC, and Forrest General Hospital stakeholders, Tara Harbart, Heart Failure Registered Nurse and Heart Failure Task Force members. The author thanks Dr. Hearn and Dr. Higginson for use of their Patient Care Outcome Scale, which gave meaning to the study. 


\section{TABLE OF CONTENTS}

ABSTRACT ii

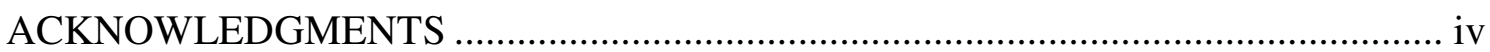

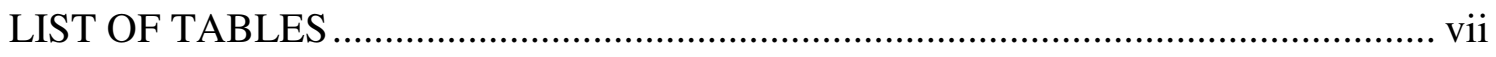

LIST OF ABBREVIATIONS ........................................................................... viii

\section{CHAPTER}

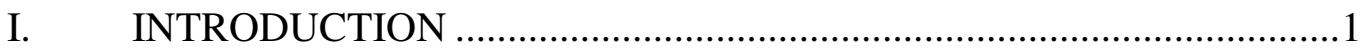

Needs Assessment

Rationale

Problem Recognition

II. LITERATURE REVIEW

Cost Burdens

Impact of Problem on Population

Self-Management and Clinical Deterioration

Milieu and Magnitude of Excess Readmissions Problem

Evidence-Based Solutions

III. PROJECT DESIGN

IRB Project Proposal

Project Management Tools

Planning and Evaluation

Implementation

Data Analysis and Results

IV. SUMMARY

Discussion

Limitations

Implications

Suggestions for Future Directions

Summary and Conclusions

Plans for Dissemination 


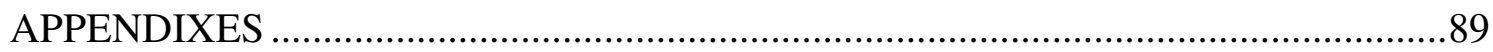

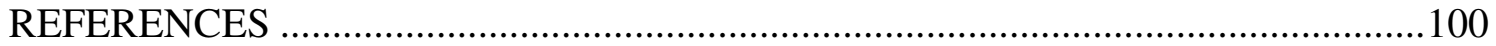




\section{LIST OF TABLES}

Table

1. Loopback Readmission Rates and Hospital Compare Data ..............................17

2. Heart Failure Hospital Process of Care Measures ...........................................19

3. Hospital Process of Care Measures for Patient Experiences .............................20

4. Medicare Payment and Volume Data for Forrest General Hospital ...................30

5. Cost Benefit Analysis for Reducing 30-day Readmissions in a Hospital with Heart Failure Clinic Affiliation .................................................. 31

6. The Essentials of Doctoral Education for Advanced Nursing Practice ...............36

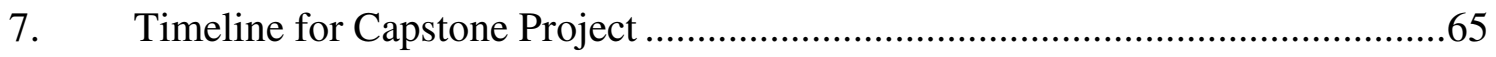




\section{LIST OF ABBREVIATIONS}

\begin{tabular}{|c|c|}
\hline AACN & American Association of Colleges of Nursing \\
\hline ACC & American College of Cardiology \\
\hline ACNP & American College of Nurse Practitioners \\
\hline AHA & American Heart Association \\
\hline ANOVA & analysis of variance \\
\hline CBA & Cost benefit analysis \\
\hline $\mathrm{CHF}$ & congestive heart failure \\
\hline CMS & Centers for Medicare and Medicaid Services \\
\hline CVD & Cardiovascular disease \\
\hline DC & discharge \\
\hline DM & disease management \\
\hline DNP & Doctorate of Nursing Practice \\
\hline DRG & diagnosis related groups \\
\hline EBP & Evidence-based practice \\
\hline FGH & Forrest General Hospital \\
\hline FY & Fiscal Year \\
\hline HCAHPS & $\begin{array}{l}\text { Hospital Consumer Assessment of Healthcare Providers and } \\
\text { Systems }\end{array}$ \\
\hline $\mathrm{HF}$ & heart failure \\
\hline HFSA & Heart Failure Society of America \\
\hline HRRP & hospital readmission reduction program \\
\hline ICER & incremental cost effectiveness ratio \\
\hline IHI & Institute for Healthcare Improvement \\
\hline IOM & Institute of Medicine \\
\hline IPPS & Inpatient Prospective Payment System \\
\hline IRB & Institutional Review Board \\
\hline JHNEBP & Johns Hopkins Nursing Evidence-Based Practice Model \\
\hline $\mathrm{LV}$ & left ventricular \\
\hline LVH & left ventricular hypertrophy \\
\hline MedPAC & Medicare Payment Advisory Commission \\
\hline NQF & National Quality Forum \\
\hline NYHA & New York Heart Association \\
\hline PET & problem identification, evidence, and translation \\
\hline PICOT & population, intervention, comparison, outcome and time \\
\hline POS & Patient Care Outcome Scale \\
\hline Project RED & reengineered hospital DC process \\
\hline QALY & quality adjusted life years \\
\hline QOL & quality of life \\
\hline RAC & Recovery Audit Contractors Program \\
\hline RCT & randomized controlled clinical trials \\
\hline RSRRs & Risk Standardized Readmission Rates \\
\hline STAAR & IHI's STate Action on Avoidable Rehospitalizations \\
\hline USM & The University of Southern Mississippi \\
\hline
\end{tabular}

viii 


\section{CHAPTER I}

\section{INTRODUCTION}

This Capstone Project focused on the subject of elder heart failure patients who had been discharged from the hospital. The purpose of the study was to collect information about heart failure symptoms related to recent problems with selfmanagement from the patients themselves. Patient-reported outcomes are rare in the context of this research. An intervention tool was disseminated prior to data collection that highlighted actions to take with acute symptoms (see Appendix A).

Findings of the study emphasized the importance of face-to-face communication by healthcare providers with heart failure patients and their families. The discharge transition phase following hospitalization is a critical phase when clinical errors occur. Extreme fatigue, shortness of breath, and anxiety were several major problems reported. Staff was missing some of the symptoms that patients and caregivers were reporting.

The primary purpose of this project was to determine factors influencing worsening symptoms of heart failure (HF) in a sample of elder heart failure patients that could affect readmission to the hospital following discharge. The second goal was to analyze psychometric quality-of-life outcome variables using the Palliative Care Outcome Scale, an acute care management tool entitled Red Flags I Need to Know: Heart Failure Action Plan, of functional status from the patient, caregiver, and staff to draw conclusions about the patient's self-care management.

The question for the study was to explore whether patient education about selfcare management of acute symptoms compared to usual care for heart failure reduces hospital readmissions within 30 days of discharge from the hospital. Exploration was in 
the context of patients with acute symptoms making a decision to take action with acute symptoms.

For this project the Palliative Care Outcome Scale (POS) instrument was utilized (Hearn \& Higginson, 1999). POS data were extracted from the interview questionnaire instrument, and patient responses were recorded for quantitative and qualitative findings. Collaboration with Pioneerhealth LLC and stakeholders on the Heart Failure Task Force was positive. The champion and major stakeholders were supportive of the project.

The primary goal to determine factors that influence worsening symptoms of HF syndrome was met by several outcome objectives. First, the project leader met with the clinical site champion on 9 days to observe teaching strategies with the HF population prior to implementation of the research project at Pioneerhealth LLC. Telehealth HF monitor installation was observed with Forrest General Hospital (FGH) Home Care and Hospice agency in patient homes for 2 days. Clinical observation visits were performed at Pioneerhealth LLC on October 6, November 21, December 20 and 22, 2011, January 14, March 6 and 27, May 29, and June 5, 2012. Observation was made with home health nurses visiting telehealth patients on February 15 and March 7, 2012. A second outcome was for the ACNP Director of Pioneerhealth LLC to distribute the intervention tool, Red Flags I Need to Know: Heart Failure Action Plan, to a purposive sample of $n$ $=10 \mathrm{HF}$ patients and schedule them for the survey interviews at their next regularly scheduled return visit to the clinic. Dissemination of the acute symptom management tool and scheduling interview appointments occurred from June 5, 2012, to June 26, 2012, by project champion Brad Massey. 
A third outcome in meeting the primary goal of examining patient perceptions was met by conducting the exploration of HF perceptions in the clinical setting with recorded interviews and administration of the POS survey instrument. The dates of the study interviews and data collection were June 12, 19, 26, and July 3 and 10, 2012, at Pioneerhealth LLC. The main themes of heart failure management from the HF patient's perspective were coded and determined. The research question was to qualitatively explore HF patient perceptions of their worst problems to determine factors that aggravate symptoms of HF. Exploration was in the context of patients making a decision to take action due to the occurrence of acute symptoms.

The patient, caregiver, and staff completed separate POS questionnaires. These three components were compared quantitatively to analyze patient responses to their quality-of-life status at their return clinic visit. The project leader collected patient, caregiver, and healthcare provider data of psychometric functional status by measurement of the 10 quality-of-life (QOL) outcome variables. These 10 psychometric QOL outcome variables from the POS instrument at a point in time provided data for the researcher to draw conclusions about self-care management and adherence patterns in the sample HF population.

The POS multidimensional outcomes examined were psychological, social, spiritual, and physical domains that are described by the patient, caregiver, and healthcare provider describing patient quality of life (Aspinal et al., 2011; Bausewein, Grice, Simon, \& Higginson, 2011). The specific physical symptoms such as pain, breathlessness, and fatigue are valuable when specifically measured in HF research (Aspinal et al., 2011; Bausewein et al., 2011). 
A long-term goal, which was not within the timeframe of this project, is to see a reduction of excessive HF readmissions compared to the national average. It is the objective of the researcher to trend data from April 2010 to March 2013, using the Hospital Compare web site to compare national HF 30-day readmission rates with previous rates. A second long-term objective is to see an improvement in Hospital Consumer Assessment of Healthcare Providers and Systems (HCAHPS) scores for medication teaching, reflecting patients' satisfaction with their healthcare in the hospital setting. However, these long-term objectives did not fit within the timeframe of this project and will therefore not be discussed further.

Evaluation and dissemination phase objectives included statistical analysis of the quantitative data and expert reviews of qualitative data for themes and meanings. Collaboration with the project champion and hospital Institutional Review Board (IRB) Chair to provide research study findings was planned following completion of evaluation. Reports of findings were planned to be presented to Forrest General Hospital's Research Committee as scheduled by the FGH IRB Chair upon completion of the Capstone Project.

The mission statement of this Capstone Project was to provide an intervention for an elder HF population in Mississippi that would improve patient knowledge of acute symptom management and potentially result in improved quality of life. Processing knowledge should aid patients in making better decisions about self-care management. Methods utilized to address the problem of excess readmissions included conducting an in-depth literature review that demonstrated the need for the proposed intervention and performing a needs assessment of gaps in clinical practice. The project leader had direct immersion into a heart failure patient population in a clinical setting to 
assess current teaching patterns of practice. The intervention was a pamphlet tool on acute HF management that was to be disseminated prior to collection of data. A research study was conducted on a sample elder HF, which demonstrated the efficacy of the intervention. The intervention is reproducible in multiple settings.

Needs Assessment

\section{Patient Population}

The focus of this project centered on the problem of excessive 30-day readmissions to the hospital in the heart failure (HF) population. The population included elderly patients aged 65 years or older diagnosed with HF who were referred to and being seen by a healthcare provider within 30 days of discharge from the hospital. Patients were seen by a nurse practitioner in the heart failure clinic within a week to 10 days following discharge. The patients returned to the clinic every 2 weeks with individual progression to monthly visits until discharge to the home setting. The patients were New York Heart Association (NYHA) classification Stages III and IV (ACC/AHA, 2011).

Information about the patient population collected included cardiac diagnosis, NYHA stage, ejection fraction, and systolic blood pressure. Sociodemographic data were retrieved. Internal organizational information and external data from websites were utilized for benchmarks and costs. Direct observation of nurse assessment and cardiac teaching performed with HF patients were carried out by the project leader at Pioneer Healthcare LLC and at Forrest General Home Care and Hospice.

Sponsor and Stakeholders

Major stakeholders in the Capstone Project were affiliated with Forrest General Hospital, a 512-bed, Level II regional trauma center hospital system located in 
Hattiesburg, MS. The stakeholders were the following: Tara Harbart, HF Registered Nurse; Susan Murphy, Quality Improvement Coordinator; Melita Miller, Director of Forrest General Home Care and Hospice; and Brad Massey, CEO of Pioneer Healthcare LLC. Brad Massey, American College of Nurse Practitioners (ACNP), was the champion and major sponsor. All members of the HF Task Force were indirectly related to the project.

The five key stakeholders in healthcare are consumers, providers, payers, suppliers, and regulators. Consumers in this project were patients discharged from the hospital who were referred to the HF clinic within 2 weeks of discharge. The patients were enrolled in Medicare insurance plans for healthcare. Providers consisted of nurses, nurse practitioners, physicians, social workers, pharmacists, and physical or respiratory therapists. Organizational providers were the hospital, heart failure clinic, long-term care facilities, and the home care agency.

The federal government is a major payer of healthcare services, covering over $50 \%$ of total healthcare revenue. Third-party payers are insurance companies, employers, or government agencies that provide healthcare insurance. Under the Medicare prospective payment system, the payer determines how much will be paid to provide healthcare before services are rendered. In HF the fee-for-service system reimburses the provider a specific amount of money for each service that is provided. Federal regulators set regulations and standards that providers must meet and have the overall responsibility for both achieving quality and holding down costs. Utilization review was a cost reduction strategy established in 1972 that utilized several mechanisms (Dunham-Taylor \& Pinczuk, 2010). Several significant components of 
utilization review for HF are preadmission certification, concurrent review, discharge planning, and case management.

Organizational Assessment

The project was conducted at Pioneerhealth LLC. The community refers to this as the congestive heart failure (CHF) clinic. Pioneerhealth has a contractual agreement with FGH. The mission of FGH is embedded in an acronym:

We CARE: Cultivate an environment of courtesy and compassion, advance the practice of medicine through education, unparalleled commitment, and world class services, recognize and emphasize the patient experience, and expect the most ... The most skilled, the most dedicated, the most concerned physicians and staff. (FGH, 2011, p. 1)

The vision of FGH (2011) is to "define the healthcare experience by providing world class care" (p. 1). With a contractual agreement, Pioneerhealth LLC shares the same mission as FGH.

The mission of the Capstone Project was to provide an intervention that would improve cardiac teaching about acute symptom management for an elder HF population resulting in improved self-management behaviors. Major components of the project reflected in the organizational mission were education, commitment, patient experience, and the expectation by patients to have the most skilled and dedicated physicians and staff members.

Internal stakeholders at FGH were the telemetry floor and emergency room department directors, patients, medical director, chief financial officer, site administrator, nurses, case managers, and members of the HF Task Force. External stakeholders were regulatory agencies, insurers, Centers for Medicare and Medicaid 
Services (CMS), members of the community, pharmacists, families and caregivers, support groups, and health advocacy organizations. Loopback Analytics is an external statistical company that utilizes proprietary methodology to calculate the likelihood of readmission for discharged HF patients, enabling hospitals to devote resources to the most critically important and at-risk patients. A Loopback Analytics representative was and continues to be present at all FGH HF Task Force meetings.

In 2009 FGH formed the HF Task Force, which is comprised of physicians, nurses, pharmacists, social workers, dietitians, and other caregivers to monitor the hospital's progress and continually implement changes that improve patient care. In 2010 the hospital opened the outpatient CHF clinic (Pioneer Healthcare LLC) that offers medication management, education, and support to decrease HF patient symptoms and improve quality of life. The clinic's initial visits as it opened in February of 2010 numbered five and grew to a total of 127 by the end of the year. In 2011 initial and follow-up visits totaled 529. Massey, ACNP, is the Nurse Practitioner and CEO of Pioneerhealth LLC. He personally communicates face-to-face with all referred patients. The hospital and clinic utilize CMS 30-day all-cause Risk Standardized Readmission Rates (RSRRs) outcome measures for Medicare fee-forservice patients admitted to the hospital for HF.

The hospital's readmission report card is reviewed monthly by the HF Task Force. The quality benchmarks from the U.S. Department of Health and Human Services (USDHHS) are reviewed as part of the Hospital Inpatient Quality Reporting Program. The 2011 release of rates reflect the percentages that were calculated from Medicare data on patients discharged between July 1, 2007, and June 30, 2010 (USDHHS, 2011). The crude 30-day FGH HF readmission rate for all payers was 
29.5\%. By comparison, the CMS Reported Average of U.S. 30-day readmission rate was $24.8 \%$ (USDHHS, 2011). The adjusted readmission rate of FGH was listed as worse than the U.S. national rate. The CMS Reported Averages are benchmark measures which CMS publishes that are determined by adding all the individual hospital ratios and dividing by the number of hospitals. Every hospital is weighted equally in this calculation regardless of the number of patients treated. The most recent numbers for the study were from 2010. The national U.S. figures are completed annually and stay one year behind actual data (USDHHS, 2011).

Public reporting of readmission outcomes began in 2009 by CMS as a measure of performance quality (Ross et al., 2010). The 30-day RSRRs among fee-for-service beneficiaries discharged after HF hospitalization from all U.S. acute care nonfederal hospitals are reported. This was supported by reports from the Institute of Medicine (IOM) and Medicare Payment Advisory Commission (MedPAC) that identified hospital readmissions as potential indicators of poor care or missed opportunities to better coordinate care (Ross et al., 2010). The National Quality Forum (NQF) endorsed RSRRs as a measure of hospital performance. They are aligned with the American Heart Association (AHA) and American College of Cardiology (ACC) standards for statistical models used for calculation and public reporting of health outcomes and efficiency measures (ACC/AHA, 2011; Krumholz et al., 2009; Ross et al., 2010). These readmission measures were endorsed by the NQF and are reported publicly by USDHHS (2010). The readmission rates assess readmissions for any reason within 30 days of discharge from a hospital stay. The study was based on original ACC/AHA guidelines for the diagnosis and management of HF (Hunt et al., 2001; Jessup et al., 2009). 
Studies were variable prior to the public reporting period. The lack of improvement during this period may suggest ineffective strategies for preventing readmissions. It remains to be seen whether public reporting will affect current rates (CMS, 2010a). According to the CMS, there has not been any recent national or regional improvement in hospital readmission care among Medicare beneficiaries discharged alive after HF hospitalization. Recent national RSRRs approached 25\% for the most common discharge diagnosis. The CMS hopes that public reporting of RSRRs for all hospitals heightens healthcare quality improvement opportunities (Ross et al., 2010).

Hospital referral regions with RSRRs significantly higher than the national average (worse performers) are mostly in sections of the Midwest and Middle Atlantic regions (CMS, 2010a). Tracking the change of RSRRs over time helps monitor whether quality of care is improved and efforts to reduce readmissions are effective. Jackson, MS, reported a mean RSRR of 25.3\% compared to Pacific and Mountain regions, such as Ogden, Utah, with 18.2\% from 2006 to 2008 (CMS, 2010a). Mississippi was classified as a worse performer. Hospital referral regions with heart failure RSRRs significantly lower than the national average (better performers) are predominantly in the West and East Central regions (CMS, 2010a).

Available Resources

The Pioneerhealth LLC clinic was the primary site for the Capstone Project and intervention. Statistical support was offered in association with Loopback Analytics by Brad Massey. Loopback Analytics is a business assistance service that assists FGH with customer follow-up to improve customer outcomes. One aim of Loopback is to support readmission reduction efforts. Office space with a room appropriate for patient 
interviews at the clinic was available and offered free of charge. Massey offered to provide assistance in the purposive sampling of HF patients and to distribute the acute care management pamphlet tool prior to study implementation. The time Massey provided in assisting with the research study was offered free of charge.

The POS instrument was utilized free of charge provided the project leader gave credit to persons that developed the instrument (Hearn \& Higginson, 1999). The primary means of communication for the project was existing electronic mail accounts between USM and FGH and ongoing communication between project leader and project champion. The expense of intervention pamphlets and instrument costs were absorbed by the project leader. There were no anticipated risks to taking part in the study. There were no hidden meanings on the questionnaire. The patients were asked about the main problems experienced when their heart failure worsened. This question was answered as the participant chose to answer. The answers collected provided information about self-care management that might help guide nursing care for $\mathrm{HF}$ patients in the future. The increased knowledge about symptom management may increase the quality of life for participants. There were no charges incurred to research study participants and no monetary compensation awarded for the interview.

\section{Desired Outcomes}

The main aim of the study was to explore patient perceptions of their heart failure syndrome management and to measure psychometric quality-of-life outcome variables, such as anxiety, self-worth, and support, in a sample of heart failure patients recently discharged from the hospital. The sample population was HF patients aged 65 years and older in NYHA classification ACC/AHA Stages III to IV (Hunt et al., 2009). Desired outcomes were for the champion to distribute the intervention tool with 
scheduling of patient interviews and to administer the survey instrument to determine factors that influence worsening symptoms of HF from patient interviews. Qualitative outcomes were analyzed by two reviewers from Question 11 of the POS instrument. Quantitative analyses were performed with analysis of variance (ANOVA) by statistician Dr. J. T. Johnson. Comparisons were made between patient perception scores, staff scores, and caregiver scores.

A new staging approach to classifying HF was developed originally in the 2001 ACC/AHA Guidelines (Hunt et al., 2001). Both development and progression of the disease were emphasized by identifying four stages involved in HF syndrome (see Appendix B). Stages A and B patients are defined as those with risk factors that undoubtedly predispose to the development of HF (Hunt et al., 2001; Hunt et al., 2009). Stages A and B are not HF, but early identification of patients at risk for developing HF can be made by healthcare providers. Patients with coronary artery disease, hypertension, or diabetes mellitus that have not yet demonstrated impaired left ventricular (LV) function or hypertrophy are considered Stage A, while patients who are asymptomatic but demonstrate LV hypertrophy $(\mathrm{LVH})$ and/or impaired LV function are designated as Stage B. The majority of HF patients are Stage C, which denotes patients with existing or past symptoms of HF associated with underlying structural heart disease. Stage D designates patients with truly refractory HF who might be entitled to specialized or advanced treatment strategies such as mechanical circulatory support, continuous inotropic infusions, or cardiac transplantation, or end-of-life care such as hospice (Hunt et al., 2009). This classification recognizes the established risk factors and structural prerequisites for HF development and that the introduction of interventions prior to the appearance of LV dysfunction can reduce mortality and 
morbidity of HF populations. This classification system complements the NYHA functional classification, which primarily gauges the severity of symptoms in Stage C or D patients (Hunt et al., 2009). This system does not replace the NYHA classification. For example, a patient who has already developed the clinical syndrome of HF (Stage C) would never return to Stage B (never had HF), and therapies recommended for Stage C would be appropriate even if this patient was in NYHA class I (Bonow et al., 2005; Hunt et al., 2009).

This demographic cohort of HF patients often faces decisions such as the transition challenge of whether to be a part of hospice. Symptom management refers to self-care or self-management processes whereby patients and/or their caregivers perform daily activities that serve to maintain or restore health and well-being and manage chronic illness (Moser \& Watkins, 2008). Education at discharge remains a vital and important component of improving self-care and outcomes in heart failure. The lack of appropriate discharge teaching contributes to adverse events and increased readmissions (Greenwald, Denham, \& Jack, 2007; Paul, 2008). A structured system of patient and family or caregiver education involving a multidisciplinary team should emphasize medication adherence, sodium and fluid restrictions, and the recognition of signs and symptoms that may indicate progression of disease. Paul (2008) maintains that these structured education components might be as important as ensuring that patients are prescribed the correct medical therapy.

The POS instrument operationalizes stressful situations of HF patients in terms of three problem circumstances in line with the World Health Organization (WHO) definition of health. The WHO defines health as a state of complete physical, mental, and social well-being and not merely the absence of disease or infirmity (WHO, 2012). 
The psychometric outcomes address all three of these situations that may present stress to the patient. The three situations concern medical problems such as (a) pain or other symptoms, (b) psychological problems like anxiety and self-worth, and (c) social problems such as family anxiety or support. With application of the transactional model of stress theory (Bausewein, Daveson, Benalia, Simon, \& Higginson, 2012; Hearn \& Higginson, 1999; Lazarus et al., 1985; Rice, 2000), these patient-problem circumstances are approached cognitively by confronting the three types of situations, while avoidance strategies are aimed at distraction from problem situations (Lazarus et al., 1985; Rice, 2000). Psychometric outcome measures can increase the cooperation and motivation of the patient and caregiver during and after the intervention administration (Bausewein et al., 2012). The user centeredness and psychometric properties of outcome measures are key features of appropriate evidence that an intervention works (Greenhalgh, Long, Brettle, \& Grant, 1998).

Qualitative outcomes originated from data collected or patient interview feedback from POS questionnaire item 11. The project leader asked the patient an open-ended question: If any, what have been your main problems in the last 30 days?" Patient problems are conceptualized with the context of heart failure as recognized by the Heart Failure Society of America (HFSA). The HFSA describes early symptoms of heart failure as a weight gain or loss of 2 or more pounds in one day or 4 pounds in one week, swelling in extremities or abdomen, persistent cough or chest congestion, increasing fatigue, loss of appetite or nausea, feeling of bloating in stomach, confusion or restlessness, intermittent or mild shortness of breath, or lightheadedness (HFSA, 2006). The HFSA describes worsening of symptoms, such as chest discomfort or pain that lasts more than 15 minutes is not relieved with rest or nitroglycerin, severe or 
persistent shortness of breath, and fainting or passing out. Other urgent symptoms are increasing shortness of breath or new shortness of breath while resting, trouble sleeping due to difficulty breathing, a need to sleep sitting up, fast or irregular heartbeats or a racing heart that persists with lightheadedness, or coughing up frothy or pink sputum (HFSA, 2006).

A first probe question was necessary for some participants following the openended question: Tell me more about your problems. If there was still no response, a second probe question was asked: How does that make you feel? The question warranted direct patient feedback so that the data would reflect what patients were feeling in their hearts and thinking in their minds (Bausewein et al., 2012). Feedback from patients themselves reflects the gold standard in patient outcome reporting. Patient-stated perceptions portray what quantitative numbers cannot signify. Only the patient can know what is in his or her heart and mind. Oftentimes if a staff member answers questions for the patient about symptoms, such as pain or anxiety, the symptoms are underestimated (Bausewein et al., 2012).

Quantitative analyses were performed on patient and caregiver responses about individual questions regarding their anxiety or hopelessness and other psychometric measures (Hearn \& Higginson, 1999). These quality-of-life outcomes were patientreported psychometric measures that reflected their functional status at a point in time. The instrument variables included pain, other symptoms, anxiety, family anxiety, information about their illness, able to share feelings, life worthwhile (depression), if they felt good about themselves (self-worth), time wasted, and practical problems being addressed. Functional status reflects how the patient performs activities of daily living (ADL). The zero to four Likert scale questions contained physical, psychological, 
spiritual, practical, emotional, and psychosocial domains. A moderate score of 20 out of 40 possible points typically indicates the patient has a moderate degree of deterioration (Aspinal et al., 2011). As the sum of QOL scores increase, the patient's clinical deterioration increases. A global score generated by summing all the scores for each patient can be useful in providing an insight into the patient's overall condition. A score of 20 indicates moderate palliative care needs. The differences between patients and staff can highlight issues for follow-up, as well as identify areas for development of nursing practice and staff education. The differences in individual questions can highlight specific needs for this heart failure population.

Long-term goals of this project were that the HCAHPS scores would show improvement for medication explanations and discharge information for recovery at home following intervention strategies. The HCAHPS scores depict national survey results of patient experiences during a recent hospital stay. These scores reflect all patients discharged from the hospital including HF patients. It was also anticipated that improvements be realized of crude 30-day HF readmission rates for FGH compared to U.S. averages of readmission rates (USDHHS, 2011). These figures, however, are measured on an annual basis and the long-term outcomes are not within the scope of this project.

Benchmark comparisons were utilized to identify a gap in practice, compile evidence for the problem and intervention, and translate findings. The Hospital Compare (USDHHS, 2011) reflects improvements of crude 30-day HF readmission rates for hospitals in the U.S. The 30-day adjusted readmission rate for FGH for 2011 was $29.5 \%$. This figure was compiled of cumulative statistics for 3 years from 2007 to 
2010. This adjusted readmission rate was categorized as worse than the U.S. national rate by CMS Hospital Compare (USDHHS, 2011) (see Table 1).

Table 1

Loopback Readmission Rates and Hospital Compare Data

\begin{tabular}{llll}
\hline Year & $\begin{array}{l}\text { FGH heart failure } \\
\text { readmission rates } \\
\text { by Loopback }\end{array}$ & $\begin{array}{l}\text { CMS aggregate data } \\
\text { July 1, 2007, through } \\
\text { June 30, 2010 }\end{array}$ & $\begin{array}{l}\text { U.S. 30-day } \\
\text { readmission } \\
\text { rate CMS }\end{array}$ \\
\hline 2007 & $28.9 \%$ & for FGH) & (for FGH) \\
2008 & $25.4 \%$ & & $24.8 \%$ \\
2010 & $25.3 \%$ & $29.5 \%$ & \\
\hline
\end{tabular}

Continued improvement of readmission rates is necessary to avoid penalties for reimbursement by CMS. Of 4,857 hospitals in the U.S., 117 hospitals were better than the U.S. national rate, and 199 hospitals were worse than the U.S. national rate (USDHHS, 2011). CMS instituted a policy of using 3 years of discharge data and a minimum of 25 cases to compute an excess readmission ratio of each applicable condition for each hospital. For FY 2013 the excess readmission ratio will be based on all discharges occurring during the 3-year period of July 1, 2008, to June 30, 2011, (CMS, 2012). Reform efforts related to the reduction of hospital readmissions began a decade ago with IOM (2002) reports on quality and safety, the NQF formation, valuebased purchasing, nonpayment for hospital acquired conditions, the need for improved outcomes, and penalties for excessive readmissions (CMS, 2010b). 
Loopback Analytics (2011) tracks HF rates for FGH in readmission reduction efforts. These trends are helpful to the HF Task Force in the continuous analysis of outcomes.

Loopback readmission rates are not the same as the CMS readmission rates for FGH (Loopback Analytics, 2011). For example, CMS data list 29.5\% for 2011, while Loopback lists $26.6 \%$. These percentages reflect the work of the HF Task Force in determining each individual readmission and discharge that accounts for the CMS figures. Each patient is discussed and followed up by the respective department within the hospital, the nursing home, home health, or the heart failure clinic. All DRGs and charts are audited, as well, in an effort to reduce HF readmissions. In addition, the HF clinic represents separate readmission data. Reported readmissions for the clinic were $6.5 \%$ and $19.8 \%$, respectively, in the third and fourth quarters of 2010 , decidedly less than hospital readmissions.

Three of the best practices of the ACC/AHA Physician Consortium for Performance Improvement Performance Measurement Set (USDHHS, 2011; Jessup et al., 2009) were largely related to this Capstone study (see Table 2). These measures are available for public viewing. The FGH process of care measures was higher than national averages. For example, $93 \%$ of HF patients (FGH) were given DC instructions compared to national average of $90 \%$. These percentages appear positive. However, readmission rates did not reflect adherence of patients to the discharge instructions given, as evidenced by HCAHPS measures. In addition, CMS listed readmission rates at $29.5 \%$ (USDHHS, 2011) compared to U.S. readmissions average of $24.7 \%$. This reflects a gap and a need for improved practice. 
Table 2

Heart Failure Hospital Process of Care Measures

Care measures

National average

$\%$

FGH (April 2010 to

March 2011)

$\%$

$n$

HF patients given discharge

90

93

494 instructions

HF patients given an evaluation

98

100

596

of left ventricular systolic

(LVS) function

HF patients given ACE inhibitor

95

99

184

or ARB for left ventricular

systolic dysfunction (LVSD)

Source: Center for Medicare and Medicaid Services (CMS, 2010b)

The ACC/AHA Clinical Performance Measures for the Care of Adults with

Chronic Heart Failure was adopted by the ACC and AHA boards in August 2005

(Bonow et al., 2005). These measures are reviewed for currency once a year and are considered valid until updated or rescinded by the ACC/AHA Task Force on

Performance Measures (Bonow et al., 2005). Inpatient performance measures are the percentage of patients given evaluation of left ventricular systolic (LVS) function, ACE inhibitor (ACEI) or angiotensin receptor blocker (ARB) for LVSD, anticoagulant at discharge for HF patients with atrial fibrillation (AF), discharge instructions, and adult smoking cessation advice or counseling (Bonow et al., 2005). Only the last two ACC/AHA stages (Stages C and D) qualify for the diagnosis of HF and are considered for inclusion in the performance measure population. Consequently, the inpatient and outpatient performance measurements do not apply to patients with recognized risk 
factors and structural disorders that occur without left ventricular systolic dysfunction or symptoms associated with HF (Stages A and B) (Bonow et al., 2005; Hunt et al., 2001).

Patient responses that identify a gap in care are listed in Table 3 based on FGH's national survey HCAHPS scores of recent hospital stay patient experiences (USDHHS, 2011). HCAHPS scores describe medications and recovery information (DC instructions) as a problem, 59\% and 78\%, respectively. Fifty-nine percent of patients reported that staff always explained medications before administration. Seventy-eight percent of patients reported that, yes, they were given information about their recovery at home.

Table 3

Hospital Process of Care Measures for Patient Experiences

Care measures

$\begin{array}{ccc}\begin{array}{c}\text { Mississippi } \\ \text { average }\end{array} & \begin{array}{c}\text { National } \\ \text { average }\end{array} & \begin{array}{c}\text { FGH (April 2010 } \\ \text { to March 2011) }\end{array} \\ \% & \% & \%\end{array}$

Patients who reported 64 61 59 that staff "always" explained about medicines before giving it to them

Patients who reported that yes, they were given information about what to do during their recovery at home

Note. These averages were obtained from Center for Medicare and Medicaid Services (CMS, 2010b).

These numbers identify a teaching gap by nurses in spite of the process of care measures indicating that $90 \%$ of patients are given DC instructions. The scores for 
explaining medications and giving patients information about what to do for recovery at home demonstrate the need for improved patient teaching in the hospital prior to discharge (USDHHS, 2011).

These HCAHPS scores and readmission rates reflected a gap in current clinical practice. Scores can be retrieved from public websites (USDHHS, 2011).

\section{Team Selection}

Initially the project leader presented an evidence-based nursing intervention to improve discharge teaching to the cardiac team with telemetry floor manager Howard Nobles, RN. The proposed intervention was to increase face-to-face discharge nurse teaching time to one hour with patients and caregivers. The Institute for Healthcare Improvement's (IHI) 2009 survey of published evidence of effective interventions to reduce readmissions cited patient education as a major focus of nine articles reviewed (Boutwell et al., 2009). Educational interventions reviewed were primarily those consisting of additional time spent on education and self-management instruction in the inpatient setting (Boutwell et al., 2009). Discharge education consisting of a one-onone patient education session with a trained nurse educator at the time of discharge reduced the risk of rehospitalization or death over a 6-month period in post-discharge follow-up patients with chronic HF (Koelling, Johnson, Cody, \& Aaronson, 2005). This timeframe also increased self-care measure adherence (Koelling et al., 2005). Evidence-based research has focused on multidisciplinary interventions with patients at time of discharge (Boutwell et al., 2009; Naylor et al., 2004). A systematic review of randomized controlled clinical trials (RCTs) that examined self-management interventions in which patients maintain the prime role of self-monitoring and deciding when therapeutic attention is needed was associated with a reduced risk of readmissions 
for HF. It was found that patient management interventions also reduced all cause rehospitalization and lower per patient costs (Jovicic, Holroyd-Leduc, \& Straus, 2006 ). Literature suggests that nurses spend only about 8 minutes per patient on teaching during discharge transition (O'Reilly, 2011). Extended time for discharge teaching has been an effective strategy in reducing readmissions at the Evergreen Hospital Medical Center in Kirkland, Washington (Konick-McMahan, Bixby, \& McKenna, 2003; O'Reilly, 2011). The Evergreen Medical Center is a member of the STAAR (IHI's State Action on Avoidable Rehospitalizations) initiative launched in 2009. Since 2003 Evergreen focused on getting their HF patients the thorough follow-up care they need to avoid readmission. The hospital's overall readmission rate was $14 \%$ compared to the national $24.7 \%$, and the nurse practitioner-staffed outpatient clinic rate was $6 \%$ for more than 800 referred patients (O'Reilly, 2011). Patients improved 44\% on a QOL questionnaire and $26 \%$ on heart function measures. They accomplished this by identifying high-risk patients and referring them for care at the Cardiac Enhancement Center within 3 days of discharge. The first visit at Evergreen was 90 minutes long and involved a thorough explanation of medications and lifestyle changes needed to avoid further heart problems. Patients were counseled about weighing each morning, taking medications, eating a low-salt diet, and noticing potential emergency symptoms. The follow-up was every 2 weeks until medications were stabilized. The patients worked closely with their primary care physician and kept their physician in the loop (O'Reilly, 2011).

The FGH manager on the telemetry floor stated the nurses had no more time to dedicate to the task even though it was recognized as a gap in practice. He explained that his nurses had no more time to give to teaching. Considering short staffing patterns 
and current economics, the response was not surprising. Since the proposed Capstone Project intervention could not be implemented on this floor, the project needed to move forward in another direction. The project leader then approached the HF Nurse Ms. Harbart to coordinate a meeting with the CHF clinic ACNP, and the site location for the intervention was changed. Brad Massey, CEO of Pioneerhealth LLC, agreed to assist in conducting the study and to collaborate with community stakeholders for the project. Massey maintains a strong positive work relationship with community stakeholders. After several meetings some consistency was attained when working with a team for the HF project. The project leader was invited to be a member and attended HF Task Force meetings on a regular basis following several collaborative interviews with the HF nurse. It became apparent that the HF nurse wanted to defer her primary contact role to Brad Massey, CEO of Pioneerhealth LLC, for the project. Another barrier to the project was setting up conversations with cardiac physicians. Their nurses did not refer messages from a doctoral student to physicians. They understood this role only as a student shadowing the physician. The project leader networked with Dr. Robert Robbins, Cardiac and Thoracic Surgeon and Director of Cardiovascular Services at the Hattiesburg Clinic, who ranks number 6 of 144 nationally in research quality. Robbins agreed to be a contact for research publication and dissemination. The relationship of the project leader Massey began to have profound effects. He was able to contact anyone needed for the Capstone Project and readily assented to becoming the project sponsor, champion, and main collaborator. Change champions are expert clinicians, passionate about the EBP innovation, and are committed to improving the quality of care. Massey was capable of encouraging peers to adopt the innovation and arrange demonstrations of how to intervene by teaching acute care symptom 
management and medication adherence strategies. In this context, the change champion addresses potential implementation challenges, pilots the change in the patient population, and uses a multidisciplinary team to assist in implanting the innovation into the organizational processes (Titler, 2007).

Massey, champion and major sponsor, assesses and treats patients postdischarge at Pioneerhealth LLC. Massey also makes patient home and nursing home visits. Massey contacted Loopback Analytics to obtain statistical data for the project leader. Loopback enables hospitals to close the loop with patients after discharge to achieve continuous improvement in clinical outcomes. Loopback Analytics Readmission Reduction Service blends technology with live interaction of hospital care coordinators to attain significant reductions in readmissions, minimizing strain on technology resources of the hospital. Other team members were involved in the project. Tara Harbart, HF Registered Nurse, coordinates care with internal stakeholders at the hospital such as case managers and physicians. Melita Miller is Director of the FGH Home Health and Hospice Agency, where telehealth visits are made. Telehealth, where direct contact with the HF population was made by the project leader, is under the supervision of Leslie Masters. Masters assigns nurse installation of telehealth units in the home. The project leader worked directly with the HF population alongside delegated home health nurses to observe cardiac teaching and medication reconciliation post hospital discharge.

\section{Cost Benefit Analysis}

Cost benefit analysis (CBA) compares the value of an intervention with its costs. The value of interventions can be measured by willingness to accept compensation of implementation (Lee, 2009). This project was driven by regulatory requirements and 
governing bodies. The feasibility of a CBA was not appropriate. Highly qualified individuals needed to perform this analysis were not available. Fee-for-service payments and capitated systems tell decision makers what procedures are worth. Strategies such as self-care management and increased prevention as a result of clinical protocols can have significant payoff. In the case of HF interventions to reduce readmissions, the best outcomes are more costly. Healthcare facilities are forced to accept compensation that is less than the cost savings (Jencks, Williams, \& Coleman, 2009; Lee, 2009). The treatment of HF is a business whether the institution is profit or nonprofit (Bogaev, 2010).

Nursing interventions have shown a decrease in readmission costs in the past. A telemanagement program for HF patients' intervention led by an advanced practice nurse improved the quality of care and reduced costs to the institution (Delgado-Passler $\&$ McCaffrey, 2006). Heart failure rehospitalization rates at 3 months were reduced by 45.7\%, and HF rehospitalization rates at 6 months were decreased by $47.8 \%$. Even after the costs of the intervention were deducted, a cost savings was realized (DelgadoPassler \& McCaffrey, 2006). This was not an isolated case. Several such studies found that a cost savings was realized following HF management interventions. Medicare was in the process of implementing initiatives at that time to reduce overpayments.

The Recovery Audit Contractors (RAC) Program began to review claims on a post-payment basis to identify improper payments to providers (Hines, Yu, \& Randall, 2010). This 3-year review, which began in 2006, demonstrated the enormity of overpayments by Medicare with a recovery of nearly $\$ 700$ million. Medically unnecesary treatment of HF and shock were the most frequently claimed services for improper payment and fourth highest in dollars collected (CMS, 2008a). The RAC 
program continues to put economic pressure on hospitals to make certain that HF patients meet criteria for inpatient care and are treated in the right setting (Hines et al., 2010). As organizations track quality care indicators, such as 30-day readmission and mortality rates, the strength of programs will increase.

Hospitals are concerned about readmissions for several reasons. The fee-forservice system by Medicare rewards hospitals for discharging patients sooner, but the brunt of this is not fully understood. Some people would not consider it progress to get out of the hospital sooner when it is coupled with a $20 \%$ increase in readmissions and a $53 \%$ increase in nursing home admissions (Krumholz et al., 2009). Roughly 25\% of Medicare patients are being readmitted to the hospital within 30 days of discharge, and this is costing billions of dollars. The total direct and indirect costs of cardiovascular disease (CVD) for 2009 were $\$ 475.3$ billion (Lloyd-Jones et al., 2008). In contrast, the cost of all cancer for 2008 was estimated at $\$ 228$ billion. CVD costs more than any other diagnostic group (AHA, 2011; Lloyd-Jones et al., 2008). In 2010 the estimated direct and indirect cost of treating HF patients in the U.S. was \$39.2 billion (Wang, Zhang, Ayala, Wall, \& Fang, 2010).

During the 30 days for readmission the cost burden is shifted to the healthcare facility, and Medicare does not reimburse the hospital. The CMS began imposing financial penalties for excessive readmissions for HF beginning October of 2012 (AHA, 2011; CMS, 2010b). Hospitals in the bottom quartile on readmissions will suffer penalties in the hundreds of thousands, or perhaps millions, of dollars. The measurement period began with admissions in 2011. For healthcare organizations it is urgent that plans be identified and implemented to reduce readmissions and improve clinical outcomes. 
Hospitals receive slightly more than $\$ 6,000$ from Medicare for each HF admission, and the average stay lasts about 5.8 days (Jencks et al., 2009). HF related hospitalizations listing $\mathrm{HF}$ as a secondary diagnosis number $70 \%$. This number is significant considering the drastic increases of comorbidities in the elder population. From a public health perspective, the promotion of prevention and improvement of medical management based on the costs of readmissions could have a large payoff in terms of containing healthcare costs (Wang et al., 2010). Nationally, HF has an astonishing impact. It consumes $1 \%$ to $2 \%$ of total healthcare resources in the U.S. and is expected to increase in the future (Aranda, Johnson, \& Conti, 2009). Even though Medicare HF hospitalizations are decreasing, current HF readmission rates have not changed much over the past 10 years. These HF patients continue to have significant morbidity and one of the highest in hospital mortality rates of any HF population (Aranda et al., 2009; Ross et al., 2010).

The average cost for HF hospitalization has reached $\$ 23,077$ in recent years (Wang et al., 2010). This more than tripled from the 1990s where the average was about $\$ 7,000$. The mean hospitalization costs for HF patients 55 to 64 years was $\$ 25,400 \pm \$ 31,069$ and, depending on U.S. region, $\pm \$ 38,454$ (Wang et al., 2010). There is a paucity of evidence that any randomized clinical trials exist of cost-effective analyses that can inform policymakers sufficiently as to whether nurse management intervention improves quality of life for patients with $\mathrm{HF}$ at a reasonable cost to society (Hebert et al., 2008). Meta-analyses of RCTs suggest that nurse management programs effectively reduce rehospitalizations and sometimes improve functional status (Majumdar, McAlister, \& Furberg, 2004; McAlister, Stewart, Ferrua, \& McMurray, 2004). 
An RCT cost-effective analysis was conducted from 1999 to 2003 and from this analysis figures can be predicted for a nurse-led disease management program to reduce hospitalizations of HF patients to reduce hospitalizations (Hebert et al., 2008). The intervention was a 12-month program that involved one face-to-face encounter with a nurse and regular telephone follow-up. Costs and quality of life were higher in the nurse-managed group. In spite of increased cost to society, it was a reasonably costeffective way to reduce the burden of HF in the community (Hebert et al., 2008). Patients in the nurse management group maintained better physical functioning measured by the short form (SF-12) physical component score and had significantly fewer hospitalizations than those in usual care. Cost effectiveness was measured by using the incremental cost-effectiveness ratio (ICER), which was the difference between the nurse-managed and usual care groups (Hebert et al., 2008). The quality adjusted life years (QALYs) were estimated by translating the SF-12 physical and mental scores and QOL scores (Hebert et al., 2008). The definition of QALY is a year of life adjusted for its quality or value. A year in perfect health is considered equal to 1.0 QALY. The value of a year in poor health would be discounted. For example, a year bedridden might have a value equal to 0.5 QALY (Medical Dictionary, 2012). A cost-effective analysis estimated costs from a societal perspective including medical and intervention costs.

Over a 12-month period this nurse-led disease management program for HF patients improved QOL at an expected cost to society of $<\$ 25,000$ per QALY gained (Hebert et al., 2008). Intervention costs of $\$ 2,177$ per patient were more than offset by reduced hospital costs $(\$ 2,378 /$ patient $)$, but higher costs for outpatient medications, 
home healthcare, and procedures prevented the intervention from being cost effective over the 12-month study.

Nurse-led disease management for $\mathrm{HF}$ at $<\$ 25,000$ per QALY lies within the range that is considered a reasonable cost to gain one year of healthy life (Hebert et al., 2008). Patients with Class III or IV HF showed improved QALY, but the costs were also higher. If this nurse management intervention covered all HF patients with a costeffective analysis of $<\$ 5,800$ per QALY gained, it would be unlikely to be cost-saving for the Medicare program. According to Hebert et al. (2008), no experimental evidence of nurse management for HF justifies a societal cost saving. Their findings match results of the Medicare demonstration project that randomly assigned patients with HF to disease management and found no evidence that nurse management interventions were cost saving. Another consideration in disease management was that long-term management was found to be more effective than short-term and low-risk disease management (Chan, Heidenreich, Weinstein, \& Fonarow, 2008).

The national average CMS Medicare reimbursements and volume data for HF and shock at FGH are listed in Table 4. Medicinal drugs, equipment, and supplies are included in figures from USDHHS (2011). The table compares three highest diagnosis related groups (DRGs) for HF at FGH. The majority of the project population was admitted with DRG 291: heart failure and shock. It is apparent that $\$ 9,033$ does not reimburse average costs of $\$ 23,077$ per patient visit (Wang et al., 2010). 
Table 4

Medicare Payment and Volume Data for Forrest General Hospital

October 2009

to September

2010
Median Medicare

payment to

hospital
Medicare patients

treated

$N=430$

Heart failure and shock

$\$ 4,291$

62

w/o CC/MCC MS-DRG 293

Heart failure and shock

$\$ 9,033$

206

with MCC MS-DRG 291

Heart failure and shock

$\$ 6,023$

162

Note. $\mathrm{CC}=$ complication/comorbidity. $M C C=$ major complication/comorbidity. Includes medicines, medical equipment, supplies. $M S-D R G=C M S$ Medicare Severity Diagnosis Related Groups (USDHHS, 2011).

A cost-benefit analysis can be projected by estimating the incremental costs of the more expensive option for HF admission and care (Lee, 2009). The use of market data can be utilized to estimate how much consumers are willing to accept to take the risk of paying for HF care. A comparison is made of incremental costs and benefits (see Table 5) with a combination of real figures from Pioneerhealth LLC and from figures in the literature (Collins et al., 2009; Hebert et al., 2008; Wang et al., 2010). Literature suggests that the mean cost of hospitalization for the entire population is $\$ 23,077$ (Wang et al., 2010). The cost that society is willing to pay is $<\$ 25,000$ per QALY gained (Hebert et al., 2008) and as high as \$50,000 per HF hospital stay of QALY (Collins et al., 2009). 
Table 5

Cost Benefit Analysis for Reducing 30-day Readmissions in a Hospital with Heart Failure Clinic Affiliation

\begin{tabular}{|c|c|c|c|}
\hline & $\begin{array}{l}\text { Value, } \\
\text { expensive } \\
\text { option }\end{array}$ & $\begin{array}{l}\text { Cost per } \\
\text { patient }\end{array}$ & $\begin{array}{l}\text { Difference in } \\
\text { value and } \\
\text { patient cost }\end{array}$ \\
\hline \multicolumn{4}{|l|}{ Direct Medical Costs } \\
\hline $\begin{array}{l}\text { Hospitalization } \\
\text { costs, total } \\
\text { (high-risk HF) }\end{array}$ & $\$ 37,621$ & $\$ 12,014$ & $\$ 11,063^{\mathrm{a}}$ \\
\hline Physician fees & 2,200 & 800 & 1,400 \\
\hline ED visits & 250 & 106 & 144 \\
\hline Prescriptions & 900 & 1,400 & $(500)$ \\
\hline Home health staff & 9,900 & 2,500 & 7,400 \\
\hline Med equipment & 250 & 20 & 230 \\
\hline Telephone calls & 500 & 25 & 475 \\
\hline \multicolumn{4}{|c|}{$\begin{array}{l}\text { Projected Cost of Intervention } \\
\text { Pioneerhealth LLC }\end{array}$} \\
\hline $\begin{array}{c}\text { Indirect Medical Co } \\
\text { Travel expenses } \\
\text { Gas, driver }\end{array}$ & 4,000 & 950 & 3,050 \\
\hline $\begin{array}{l}\text { Special services } \\
\text { daycare, meals, } \\
\text { friend help }\end{array}$ & 10,000 & 1,100 & 8.900 \\
\hline
\end{tabular}


Table 5 (continued).

$\begin{array}{lll}\text { Value, } & \text { Cost per } & \begin{array}{l}\text { Difference in } \\ \text { expensive }\end{array} \\ \text { option } & \text { patient } & \text { patient cost }\end{array}$

Medical Equipment

Computer DSL

Labs (cannot be billed, not

face-to-face), BUN,

creatinine clearance,

CBC

Oxygen saturation

monitor

Medicare allows

with dyspnea

(per patient)

29.80

4.42

Loopback Analytics auto

Telephone calls

60.00

( 30/month)

per patient

NP Salary RHC

( 44/month)

(NP can charge $58 \%$

Coded fees; average salary

NP \$69,523)
60.00 each $\quad 60$

$=2,640 /$ month
60

0

0

0 0 
agreement, so charges are either covered by the hospital or written off. The rationale for clinic visits, as well as telehealth interventions for HF patients, is to prevent future readmissions.

Collins et al. (2009) described an analysis of a 60-year-old man with acute decompensated HF where outpatient unit admission had a reasonable marginal cost effectiveness ratio compared to emergency department discharge $(\$ 23,678 /$ life year gained). The cost-effectiveness ratio is the relationship between the effectiveness gained from a decision and the cost of the decision. The marginal cost-effectiveness ratio is the difference in cost effectiveness as the patient is followed from one intervention area to the next, such as from ED discharge to hospital admission (Collins et al., 2009). Hospital admission was found to be the most effective strategy (4.56 years) in this base case analysis. It was also the most costly at $\$ 37,621$, with a marginal cost effectiveness ratio of $\$ 246,671 /$ life year gained (Collins et al., 2009).

Several relevant cost effects may not be captured in pure cost analyses. Hospitalization costs might be two thirds of costs. Outpatient visits, medications, and procedures also consume significant resources (Liao, Allen, \& Whellan, 2008). The quality of life is adversely affected for HF patients. This relevant effect is not captured in dollar amounts of cost analysis (Liao et al., 2008).

\section{Scope of Project Defined}

The goal for HF patients is to prevent the worsening of clinical symptoms that cause readmissions within 30 days of discharge. Areas for change that exist at large are identifying the patients at risk, examining the care delivery process and facility strengths, and evaluating current priorities and quality improvement initiatives. The focus of this project was to explore perceptions that may improve adherence of HF 
patients to treatment plans during discharge transition processes, which will ultimately reduce excessive readmissions to the hospital. The proposed intervention was distribution of an acute HF symptom management tool, Red Flags I Need to Know: Heart Failure Action Plan. The recommendations of this proposal mirror IHI's reengineered hospital DC process (Project RED) of hospital-reengineered processes (Jack et al., 2009). The implementation of enhanced cardiac teaching in acute disease management strengthened the intervention in efforts to reduce excessive readmissions (Boutwell et al., 2009). Psychometric outcomes were examined with the POS instrument (Hearn \& Higginson, 1999) that reflects measurable quality-of-life outcomes of pain, other symptoms, anxiety, family anxiety, support, information, life worthwhile (later version of POS listed this as depression), self-worth, wasted time, and personal affairs at a point in time (Bausewein et al., 2011). Patient reported QOL measures are the gold standard for evaluating functional outcomes in HF. Engagement of HF patients, families, and caregivers results in reducing the need for frequent readmissions. Measurable outcomes and biomarkers for HF included patient ejection fraction and systolic blood pressure $\leq 100 \mathrm{mmHg}$. Collins et al. (2009) cited high-risk factors for HF inclusion as study outcomes rather than the reduction of hospital readmission rates. Specific biomarkers that measure changes in patient condition, such as new ischemic electrocardiogram changes, systolic blood pressure $<100 \mathrm{mmHg}$, serum sodium or blood urea nitrogen, and cardiac enzymes, would give specific changes in patient condition at a point in time (Collins et al., 2009). Biomarkers of this type are recommended over excess readmission rates for measurable outcomes in heart failure studies. For this project the definition of systolic blood pressure is used (AHA, 2012). Normal systolic blood pressure (BP) is defined as $<120 \mathrm{mmHg}$, prehypertension as 
120-139 mmHg, high BP or hypertension Stage 1 is $140-159 \mathrm{mmHg}$, high BP or hypertension Stage 2 is $160 \mathrm{mmHg}$ or higher, and hypertension crisis is defined as > $180 \mathrm{mmHg}$.

\section{Rationale \\ Essentials and Theories to Support Project Framework}

Efforts to understand how the world works are characterized by systematic, rigorous, and reproducible modes of inquiry that are referred to as science. Scientists provide systematic and responsibly supported explanations about phenomena or events in the world of human experience. The goal is to advance these explanations to the level of theoretical formulations. Theory is a valued product of scientific inquiry (Chism, 2010). The challenge of nursing science is to produce nursing theory that is relevant to practice (Chism, 2010). The Doctorate of Nursing Practice (DNP) Essentials, as shown in Table 6, recommend that DNP students have a broad base of knowledge garnered from a number of sciences besides nursing (American Association of Colleges of Nursing [AACN], 2006). The DNP Essentials recommend a foundation in biology, genomics, and the science of therapeutics, the psychosocial sciences, and the science of complex organizational structures (Chism, 2010). The research-focused Doctor of Philosophy (PhD) develops theory for nursing practice. The DNP uses theory in practice. 
Table 6

The Essentials of Doctoral Education for Advanced Nursing Practice

\section{DNP Essentials}

\begin{tabular}{|c|c|}
\hline I & Scientific Underpinnings for Practice \\
\hline II & $\begin{array}{l}\text { Organizational and Systems Leadership for Quality Improvement } \\
\text { and Systems Thinking }\end{array}$ \\
\hline III & $\begin{array}{l}\text { Clinical Scholarship and Analytical Methods for Evidence Based } \\
\text { Practice }\end{array}$ \\
\hline IV & $\begin{array}{l}\text { Information Systems/Technology and Patient Care Technology } \\
\text { for the Improvement and Transformation of Health Care }\end{array}$ \\
\hline V & Healthcare Policy for Advocacy in Health Care \\
\hline VI & $\begin{array}{l}\text { Interprofessional Collaboration for Improving Patient and } \\
\text { Population Health Outcomes }\end{array}$ \\
\hline VII & $\begin{array}{l}\text { Clinical Prevention and Population Health for Improving the } \\
\text { Nation's Health }\end{array}$ \\
\hline VIII & Advanced Nursing Practice \\
\hline
\end{tabular}

Source: AACN, 2006.

The three DNP Essentials of the AACN (2006) most relevant to this project were Essentials I, III, and VI. The gap in practice for this project focused on the poor outcome of 30-day rehospitalizations in the elder HF population that could be due to errors in discharge processes. The development and dissemination of an acute care pamphlet addressed this clinical gap in practice that could aid in teaching during transition phases of discharge from the hospital. The gap was that $59 \%$ of the time nurses always explained medicines prior to administration, but $78 \%$ of the patients reported that they were given instructions about recovery at home. This reflects a 
discrepancy in patient teaching. Also, the gap was that patients do not understand their heart failure syndrome, symptoms, medicines, and care. The practice-focused doctoral program has rigorous and demanding expectations for scholarly approaches to the discipline, as well as a commitment to the advancement of the profession (AACN, 2006). The project leader spent clinical hours in an intense practice immersion experience with HF patients at Pioneerhealth LLC. This Capstone Project was an integral part of the integrative practice experience required of DNP students (AACN, 2006).

DNP Essential I describes the scientific foundations of nursing practice, which are based on the natural and social sciences. Nursing science has provided the field of nursing with a body of knowledge to contribute to the discipline of nursing. The integration of nursing science with knowledge from ethics, as well as the organizational, biophysical, psychological, and analytical sciences, forms the basis of this essential for the highest level of nursing practice (Chism, 2010). The utilization of science-based concepts and theories help to determine the significance and nature of the healthcare delivery phenomena, describe stratagems used to enhance healthcare delivery, and appraise outcomes.

The translation of research into practice and the dissemination and integration of new knowledge is the key concept of clinical scholarship and analytical methods for evidence-based practice in Essential III. The project leader was actively involved in nursing practice which allows for practical and applicable research investigation from the HF practice environment. Part of the clinical scholarship for evidence-based practice is to analytically and critically evaluate existing literature and practice 
outcomes within populations, followed by evaluation methodologies that improve quality in an effort to promote safe and effective patient-centered care (AACN, 2006).

Another important component of this Capstone Project was DNP Essential VI, interprofessional collaboration for improving patient and population health outcomes. In a complex healthcare environment, teamwork and collaboration among all health care disciplines must exist to accomplish nursing and IOM's goals. The project leader participated in collaboration with the HF Task Force, the CEO of Pioneerhealth, and major stakeholders at FGH in the analysis of HF issues with the goal of reducing rehospitalizations. Upon IRB approval, the project leader collaborated with the champion in implementing the research study, as well as in disseminating the intervention acute HF care pamphlet to study participants. This was categorized as a nurse-led disease management intervention in literature.

DNP Essential II, organizational and systems leadership for quality improvement, remains an integral part of the readmission reduction project in the hospital setting. The HF Task Force continues to be presented monthly by the Quality Management Director at FGH. The task of reducing heart failure readmissions remains a major focus of the current monthly collaboration meetings. The HF Task Force has since added pneumonia and stroke components to the committee agenda to identify similar positive outcomes with these chronic conditions and readmissions. Systems thinking strategies for safe practice which reflect DNP Essential II are evident from the constant input the various department leaders bring to the committee in a collaborative evaluation of readmission reduction efforts. The technology department is also an essential component of this committee, meeting DNP Essential IV to transform healthcare. 
Clinical prevention and population health to the nation's health (DNP Essential VII) are integral components in the study of HF as hospital units, physicians, nurses, pharmacists, social workers, case manager, clinics, and community resources collaborate to care for HF patients. Stephen Jencks maintains that there is no one unit or person that can be responsible for the looming problem of readmissions (Jencks et al., 2009). Communities and hospitals must make a collaborative effort to improve the clinical errors that occur with readmissions.

Nursing theory is an integral component of the collaborative work for heart failure readmission reduction efforts. A framework is a logical structure of meaning that guides the progress of a study and enables the linking of findings to the nursing body of knowledge (Burns \& Grove, 2009). Nurses must use theories to guide activities associated with nursing research, practice, and education (Fawcett, 2008). This project sought to develop an explanatory theory from data collection of patient-perceived problems that reflected self-care management of the American Heart Failure Guidelines (AHA, 2011). Grounded theory design analyzes data through a process of coding, followed by comparing and contrasting data to create categories (Terry, 2012). Data reduction categories are used to develop a theory that may emerge. There is a changing stance in literature that atheoretical research is impossible for mixed design or qualitative studies (Burns \& Grove, 2009; Fawcett, 2008). Strategies for using frameworks to guide qualitative studies and to interpret results are not clear. Anfara and Mertz (2006) describe how theoretical frameworks are used in qualitative research and the effects they have on the qualitative research process in social sciences. The framework of qualitative researchers is the context of the guide for qualitative researchers as they develop and link frameworks to existing bodies of knowledge. 
Anfara and Mertz give examples of theories that can be applied as lenses to studies conducted by qualitative researchers, which add the diversity and richness of theoretical frameworks that allow seeing the ordinary in new and different ways (Anfara \& Mertz, 2006).

Butts, Rich, and Fawcett (2012) maintain that nurses can effectively link nonnursing conceptual models and theories to nursing models and theories, if they are relevant to the nursing situation. The 1984 Lazarus and Folkman transactional model of stress (see Appendix C) links stress-related variables to health-related outcomes. When taken together, all of the constructs in their transactional model affect outcomes of adaptation (Rice, 2000), so the framework for this project was a stress and adaptation theory versus a systems theory. The person and environment interaction was viewed in terms of cause and effect. These adaptational outcomes encompass functioning in work and social living, life satisfaction or morale, and somatic health. The Lazarus and Folkman stress and adaptation theory (Lazarus et al., 1985) conceptualizes stress, coping, and health outcomes. Stress is viewed as a rubric for a complex series of subjective phenomena that include cognitive appraisals such as threat or challenge, stress emotions, coping responses, and reappraisals. Stress is experienced when the situation exceeds the resources of a person and some type of harm or loss is anticipated (Rice, 2000). Coping is a concept referring to efforts to ameliorate a perceived threat. Lazarus and Folkman divided these into emotion-focused coping (palliative) and problem-focused (direct action) coping. Adaptational outcomes are further categorized as short-term and long-term outcomes (Rice, 2000). Both the short-term and long-term outcomes encompass effective, affective, and physiological components. These 
components are a good fit for HF self-care management within the scope of nursing practice.

Grounded theory was utilized to analyze qualitative findings. The purpose of grounded theory in nursing is to try to understand the situations in which patients find themselves when only they can understand how they are feeling about their perceived symptoms (Carver, Scheier, \& Weintraub, 1989; Yu, Lee, Kwong, Thompson, \& Woo, 2008). The grounded theory approach originated in the field of nursing and remains well suited to that area (Glaser \& Strauss, 2009). An additional purpose of grounded approach is to gain an understanding of the situations in which patients find themselves when they are suffering from medical conditions about which very little is known. In such cases only the patient can understand how they are feeling about symptoms and general conditions. Grounded theory is a general methodology that can be applied to both qualitative and quantitative studies (Burns \& Grove, 2009; Glaser \& Strauss, 2009; Zaccagnini \& White, 2011). Grounded theory moves the description of what is happening to an understanding of the process by which it happens (Burns \& Grove, 2009).

Theories of Change

The coding of patient reported experiences of living with HF was examined through the lens of the 1984 Lazarus and Folkman transactional model of stress and adaptation theory (Carver et al., 1989; Glaser \& Strauss, 2009; Lazarus et al., 1985). This model depicts stress and the cognitive action to coping and adaptation (Carver et al., 1989; Lazarus et al., 1985; Yu et al., 2008). This theoretical model guided data synthesis of theme development of acute HF self-management problems and actions (Yu et al., 2008). The transactional model defines stress as an encounter between the 
patient and the environment or as a functional status that arouses awareness. This awareness brings about primary and secondary appraisals of the stressful events such as HF status or severity of symptoms. The secondary appraisal refers to the judgment of the controllability and effectiveness of the coping options associated with the stressor, as well as the anticipated progress of the stressful situation. This cognitive process takes place until adaptation occurs and is an emotion-focused coping (Carver et al., 1989; Lazarus et al., 1985). Emotion-focused coping is the more common form of coping used when events are not changeable and was formerly referred to as palliative coping (Lazarus et al., 1985; Rice, 2000). Carver et al. (1989) suggested that dispositional optimism might have implications for the manner in which people deal with stresses of life derived from their theoretical model of behavioral self-regulation (Carver et al., 1989; Lazarus et al., 1985). An assumption of the theory is that the expectations of outcomes that are successful cause people to renew their efforts to set and attain goals. If expectancies are unfavorable, the result might be reduced vigor or complete disengagement from further effort to attain goals (Bandura, 1977). With this model, the experiences of older patients living with HF could be integrated into meaningful domains. The study explored how patients perceived their symptoms in acute exacerbations of HF and how these symptoms or perceptions may have contributed to the ways in which they coped with these changes and their adaptation to HF syndrome with improved quality of life (Burns \& Grove, 2009). Quality-of-life measures were examined with POS profile scores on a zero to four Likert scale. The patient and caregiver responses were analyzed and compared to staff member responses to functional outcome measures (Hearn \& Higginson, 1999). 


\section{Problem Recognition}

\section{Identified Need}

Around 5.8 million people in the U.S. have HF. Expenditures for treating heart disease exceeds all other conditions, with $\$ 90.9$ billion spent in 2008 (CMS, 2010b; Jessup et al., 2009; USDHHS, 2011). Heart failure is currently the most costly cardiovascular disorder in the U.S. with annual expenditures estimated in excess of \$20 billion (Rich \& Nease, 1999). The calculated cost of avoidable readmissions by the CMS in 2004 was \$17.4 billion (Jencks et al., 2009; Taylor, 2010).

High readmission rates are considered a low quality care marker. Variations in HF readmissions must be evaluated. Excessive U.S. 30-day readmission rates in the elder HF population post-discharge are 24.8\% (USDHHS, 2011). FGH's readmission rate in 2010 was $29.5 \%$. Almost one third of patients discharged from the hospital are readmitted during the first 30 days (Annema, Luttik, \& Jaarsma, 2009; Joynt, Orav, \& Jha, 2011). RSRRs of Medicare beneficiaries discharged after HF hospitalization have not changed in recent years (Ross et al., 2010). In June 2007 MedPAC reported that three quarters of readmissions were potentially preventable (Greenwald et al., 2007).

Pay-for-performance initiatives will impact healthcare facilities reducing reimbursement for excessive readmissions. Hospitals and physicians could lose profits by reducing rehospitalizations. Improving the transition processes of HF patients from the hospital to their next care setting is a must for healthcare facilities.

Planning for this critical problem demands action by all community stakeholders. HF patients need superior discharge planning processes, post-discharge telephone support, specialized teams for quality management at home, and reengineered systems to address repeated episodes of hospitalizations (Jencks et al., 2009). The IHI 
recommends Project RED of hospital-reengineered discharge process of improved communication and early post-discharge follow-up with 11 key elements as one of 15 effectual interventions to reduce hospital readmissions (Boutwell et al., 2009; Jack et al., 2009). Nine components of the in-hospital setting are as follows:

1. Educate the patient about pertinent diagnoses throughout the hospital stay.

2. Make appointments for provider follow-up and post-discharge testing with patient input, coordinate these appointments with physicians and other services, and discuss importance of appointments.

3. Discuss with patient any pending in-hospital testing completed and who will follow up.

4. Organize post-discharge services making sure patient understands the importance.

5. Confirm medications with medication reconciliation by reviewing each medication and important side effects.

6. Merge the discharge plan with national guidelines and critical pathways.

7. Review suitable steps for actions to take if problems arise with telephone numbers of primary care providers, and instruct on what defines an emergency and what to do.

8. Send out discharge summary to physicians and services accepting responsibility of patient's care that contains hospitalization diagnoses and important findings, treatments for the patient, condition of patient at discharge, a complete medication reconciliation list with allergies, all pending results at time of discharge, information about consults with original records. 
9. Assess degree of understanding by asking patient and possible caregivers to explain the preparation fine points.

The after-hospital care plan includes giving the patient a discharge plan at the time of discharge with hospitalization diagnosis and comorbid conditions, discharge medication list with instructions, telephone number of primary care provider, outpatient appointments, and dates of scheduled appointments. The post-discharge pharmacist component is to call the patient and reinforce discharge plan, review medications, and solve problems (Jack et al., 2009).

Preventable readmissions result from care failures in the period immediately before or after transition from hospital to the next care setting (Jencks et al., 2009). Identification of high-risk patients is a first step in prevention. Examples are patients with a history of rehospitalization, failed return demonstration of knowledge, inpatient stay longer than expected, or those on dialysis. The FGH HF Task Force identifies high risk HF patients on a monthly basis. Adherence to self-management participation increases quality of life. As HF patients and caregivers see the importance of adherence and face barriers, they are enabled to participate effectively in self-management (Lindenfeld et al., 2010).

\section{Problem Statement}

About $90 \%$ of 30-day readmissions appear to be unplanned. Randomized clinical trials suggest that $20 \%$ to $50 \%$ of these are preventable with improved care around discharge processes (Jencks et al., 2009). Patient adherence in self-management can reduce these excessive rehospitalizations (Annema et al., 2009).

The problem statement for this evidence-based project was presented in the acronym population, intervention, comparison, outcome, and time (PICOT) format 
(Stillwell, Fineout-Overholt, Melnyk, \& Williamson, 2010a). The PICOT question was as follows: In elder HF patients who have been discharged from the hospital, does improved patient education about self-care management of acute symptoms compared to usual care reduce hospital readmissions within 30 days of discharge from the hospital? The PICOT question provides a framework for practicing evidence-based nursing. The evidence that is collected is examined to determine appropriate interventions for the population of interest (Fineout-Overholt et al., 2005; Zacagnini \& White, 2011). 


\section{CHAPTER II}

\section{LITERATURE REVIEW}

Literature surveys, research studies, and evidence databases were sourced using Agency for Healthcare Quality and Research (AHRQ), Medline, CINAHL, EBSCOhost Electronic Journals, Cochrane Collaboration Review, Joanna Briggs Institute, PubMed Central Journals, National Guideline Clearinghouse, and Scopus (SciVerse). Citations and abstracts were searched with key terms: heart failure, reduction readmissions, hospital readmit, interventions, adherence, qualitative nursing heart failure, qualitative research heart failure, palliative heart failure, outcome measures heart failure, theory heart failure, qualitative outcomes, and quality outcomes. Articles included in this review of literature were those on HF related to current interventions and guidelines, multidisciplinary efforts to reduce readmissions, self-management adherence regimens, and studies with measures directed at the reduction of hospital readmissions. Excluded from this study were cardiac articles with diagnoses other than HF or interventions not related to hospital readmissions.

Evidence-based practice (EBP) relies on research to substantiate clinical decisions (Newhouse, Dearholt, Poe, Pugh, \& White, 2007). Conceptual underpinnings of the Johns Hopkins Nursing Evidence-Based Practice Model (JHNEBP) represent the essential building blocks of professional nursing. The JHNEBP process of translating evidence into practice is described in phases beginning with identification of the practice question, followed by search and appraisal of evidence. Translation of the evidence into change or improvement in practice is the final phase. These phases of developing an EBP are described as the problem identification, evidence, and translation (PET) process (Newhouse et al., 2007; White \& Dudley-Brown, 2012). 
When the evidence supports a change in practice, the evidence in translation transpires. The change or improvement is then planned for, implemented, and evaluated. In the final phases of translation the results are disseminated to patients and community stakeholders. The PET process utilizes the PICOT approach to narrow the EBP question (Stillwell, Fineout-Overholt, Melnyk, \& Williamson, 2010b).

A key to making best practice decisions in the translation of research into practice is the utilization of evidence that is scientifically based and that has been replicated with success in repeated research and application (Zaccagnini \& White, 2011). Melnyk's hierarchy of ratings system was applied to literature searches for evaluation of evidence for practice rating in research on a 1 to 7 scale (FineoutOverholt, Melnyk, \& Schultz, 2005). Level one is the strongest level of evidential strength supported by research and contains systematic reviews or meta-analysis of RCTs, as well as clinical practice guidelines based on RCT data. Level two has evidence from one or more RCTs, and level three has evidence from a controlled trial with no randomization. Level four is classified as case control or cohort studies, while level five contains systematic reviews of descriptive or qualitative studies. Level six is a single descriptive or qualitative study, and level seven is the weakest with opinions of authorities or experts (Fineout-Overholt et al., 2005).

In nursing the best evidence refers to findings from methodologically appropriate, rigorous, and clinically relevant research that is clinically relevant for answering urgent questions (Polit \& Beck, 2008). Questions about the reliability of nursing assessment measures, the determinants of health and well-being, the meaning of health or illness, and the nature of patient experiences, as well as questions about the efficacy, safety, and cost-effectiveness of nursing interventions, are categories of best 
evidence that may not fit Melnyk's model. Confidence in the evidence is improved when the research methods are persuasive and when there have been multiple confirmatory replication studies (Polit \& Beck, 2008). Thus, the literature review consists of studies with a high rating of evidence, as well as compelling articles related to heart failure.

\section{Cost Burdens}

Cost burdens for excessive readmissions are well documented (AHA, 2011; Aranda et al., 2009; Jencks et al., 2009; Krumholz et al., 2009; Lloyd-Jones et al., 2008; Ross et al., 2010; Wang et al., 2010). Financial penalties will impact facilities in FY 2013 (AHA, 2011; CMS, 2010b).

A key retrospective cohort study by Joynt et al. (2011) examined whether hospitals with more experience in caring for HF patients provided better and more efficient care in 4,095 hospitals in the U.S. The sample was Medicare fee-for-service patients with a primary discharge diagnosis of CHF. Researchers concluded that managing $\mathrm{CHF}$ as measured by the hospital volume is associated with higher quality of care and better outcomes for patients but at a higher cost. Higher volume was associated with lower mortality but with higher costs (Joynt et al., 2011). The cost of $\mathrm{HF}$ is an economic burden that is not cost-effective for hospital organizations (Bogaev, 2010; Collins et al., 2009; Dunham-Taylor \& Pinczuk, 2010; Joynt et al., 2011; Liao et al., 2008; Wang et al., 2010).

\section{Impact of Problem on Population}

A notable reason for readmission of HF patients focuses around the discharge process. This process is also referred to as the transition process, which involves the patient from the time of discharge planning to home following discharge from the 
hospital. Improvement of the discharge process is an outstanding feature that contributes to a reduction in hospital readmissions (Annema et al., 2009; Balaban, Weissman, Samuel, \& Woolhander, 2008; Boutwell et al., 2009; Coleman, Parry, Chalmers, \& Min, 2006; Greenwald et al., 2007; Jack et al., 2009; Krumholz et al., 2002; Phillips et al., 2004; Ross et al., 2010; Shepperd et al., 2010; Wong et al., 2011). Caregivers and patients were encouraged to assert a more active role during care transitions to reduce hospitalization rates in an RCT by Coleman et al. (2006). Their trial of self-management involved transitions in the public realm and improving discharge processes.

In 2006 the NQF Consensus Standards Maintenance Committee in 2006 added the hospital discharge process as one of its safe practices for better healthcare (Greenwald et al., 2007). The reengineered hospital discharge process has 11 critical components. The NQF committee orchestrated practices across applicable requirements of the Joint Commission on Accreditation of Hospitals, the CMS, AHRQ, the Leapfrog Group, and IHI. They provided a road map that satisfies common requirements of major accrediting, purchasing, and quality of care practices. The group delineated these 11 components of what is now called the reengineered discharge or project RED (Greenwald et al., 2007).

Improving adherence that is practiced by HF patients is a factor in improvement of the discharge process. A meta-analysis by Boutwell et al. (2009) was conducted for interventions to improve discharge transition time periods of care. Early post-discharge follow-up, followup phone calls, and home visits one week after discharge, along with telemanagement, were intervention categories the IHI identified (Boutwell et al., 2009). 
Enhanced care and support at transitions or improved discharge process was the first major category that was examined (Boutwell et al., 2009).

\section{Self-Care Management and Clinical Deterioration}

Self-care management by HF patients was examined in a systematic review of 35 RCTs evaluating CHF self-management education programs with outcome measures (Boren, Wakefield, Gunlock, \& Wakefield, 2009). Educational interventions were recommended to be based on scientifically sound research evidence. Self-management education was categorized into sections of CHF knowledge with symptoms, medications, knowing when to call the practitioner, social support, fluids and diet management, and activities. Measurement of outcomes for self-care education management of patients $(N=7,413)$ showed $53 \%$ of outcomes with significant improvement in at least one study (Boren et al., 2009).

Self-management by patients as they performed their daily weights and reported symptoms of progressing HF was shown to decrease cost and increase quality of life (Konick-McMahan et al., 2003). Strategies such as self-care management and increased prevention to clinical protocols were once thought to have a significant payoff. In the case of HF interventions to reduce readmissions the best outcomes are more costly. Healthcare facilities are forced to accept compensation that is less than the cost savings (Lee, 2009). In 2006 an advanced practice nurse-led telemanagement program for HF patients improved the quality of care and reduced costs to the institution (DelgadoPassler \& McCaffrey, 2006). Heart failure rehospitalization rates at 3 months were reduced by $45.7 \%(p=0.03)$, and $\mathrm{HF}$ rehospitalization rates at 6 months were decreased by $47.8 \%(p=0.01)$. A cost savings was realized, even after the costs of the intervention were deducted (Delgado-Passler \& McCaffrey, 2006; Naylor et al., 2004). 
Naylor et al. (2004) examined the effectiveness of transitional care intervention by APNs to elder hospitalized HF patients in RCT. The intervention group had $25 \%$ lower 3-month readmissions, death, and total cost. These trends may have become apparent when improper payments to providers on claim reviews were identified by the RAC Program (Hines et al., 2010). The RAC 3-year review beginnning in 2006 demonstrated the sheer amount of Medicare overpayments that became part of CMS efforts to establish guidelines for reimbursement to facilities (CMS, 2008a). Medical treatment for HF was one of the most frequently claimed services for improper payment and fourth highest in dollars collected. This economic pressure on hospitals to make certain that HF patients meet criteria for inpatient care began to change reimbursement practices (Hines et al., 2010).

Pay-for-performance initiatives began to impact healthcare facilities, reducing reimbursement for excessive readmissions following the comprehensive healthcare reform signed into law in March of 2010 by President Obama (Stone \& Hoffman, 2011). On August 1, 2011, the CMS released its Inpatient Prospective Payment System (IPPS) final rule, wherein the hospital readmission reduction program (HRRP) would begin to penalize hospitals with high readmission rates beginning FY 2013. Medicare's fee-for-service system reimburses for volume of discharges, so hospitals and physicians stand to lose profits by reducing rehospitalizations (Stone \& Hoffman, 2011). The mandate from CMS to implement care models that reduce 30-day readmissions provides the impetus to improve the transition processes of HF patients from the hospital to their next care setting that will increase the quality of care and decrease costs (CMS, 2008b). 
The clinical deterioration of patients with end-stage HF has become more apparent in recent years. With a systematic review of measures appropriate for use in palliative care settings, Hearn and Higginson (1999) developed the Palliative Care Outcome Scale instrument. One strength of measure with the POS instrument is that both staff and patients are able to complete it across settings, which is a factor that has not been shown by any other outcome measure in palliative care (Hearn \& Higginson, 1999). Bausewein et al. (2011) conducted a systematic review of instruments that examine the psychometric functional quality-of-life outcomes as perceived by the patients themselves. The POS instrument developed by Hearn and Higginson (1999) evaluated the effectiveness of interventions. This instrument has made a considerable contribution to outcome measurement in palliative care as reflected by 44 studies over the last 10 years (Bausewein et al., 2011). Differences in POS scores highlight self-care needs and identify areas for increased cardiac education about self-management actions to take (Hearn \& Higginson, 1999). End-of-life care application to HF patients is a palliative care modality that is now an option for HF syndrome (Lorenz et al., 2008). HF patients who are NYHA stage IV classification begin to face the transitioning from HF to death as they make choices of whether to begin hospice care.

Fonarow, Adams, Abraha, Yancy, and Boscardin (2005) developed a practical bedside tool for risk stratification of patients hospitalized with acute decompensated HF at risk for mortality. The Acute Decompensated Heart Failure National Registry (ADHERE) of patients with primary diagnosis of ADHF in 263 U.S. hospitals were queried with analysis to develop the model. The model provides clinicians with a validated and practical bedside tool for mortality risk stratification (Fonarow et al., 2005). The inability of HF patients to recognize worsening symptoms that are 
antecedent to HF exacerbation is a common cause for HF readmissions (Moser et al., 2011). Moser et al. (2011) studied the inability of HF patients to recognize worsening symptoms that indicate an exacerbation of $\mathrm{HF}$, which is a common reason for readmissions of HF patients. Moser et al.'s (2011) objective was to examine the relationship between patterns of changes in HF symptoms and event-free survival in HF. They concluded that regardless of the severity of symptoms in HF, patients whose symptoms fluctuated with a pattern of improving then worsening were at a substantially greater risk for poorer survival. These patients may become accustomed to this pattern of improvement so that they do not seek treatment with worsening symptoms. Moser and Watkins (2008 proposed a conceptual framework of factors model that affects selfcare decision making in the HF population. It was suggested that major factors which influence self-care decision making in HF patients might be categorized into groups that are influenced by the course of life such as aging status, psychosocial status, health literacy, and current symptom status considering prior healthcare systems experiences. Decision making that is not working seems to be where self-care management fails, yet researchers said little attention from researchers or clinicians is evident (Moser \& Watkins, 2008). The multiple factors that are suggested to have an effect on self-care decision making in HF are interrelated and complex. These components should not be viewed by themselves as stand alone variables. Integrating the complex variables appears necessary to explain why self-care fails in elder HF patients.

Milieu and Magnitude of Excess Readmissions Problem

The cost of HF Medicare readmissions in 2004 was \$17.4 billion (Jencks et al., 2009). Jencks et al. performed a retrospective study of Medicare claims data and iterated the fact that readmit rates are an important element of President Obama's 2009 
Health Care Reform law. The study found that nearly $20 \%$ of Medicare patients discharged from the hospital were rehospitalized within 30 days and 34\% hospitalized within 90 days (Jencks et al., 2009). Jencks et al. (2009) suggested that about $90 \%$ of 30-day readmissions appear to be unplanned. RCTs propose that $20 \%$ to $50 \%$ of these are preventable with improved care around discharge processes (Jencks et al., 2009). Jencks was the lead author of this landmark study. He had previously become an independent consultant in healthcare quality and safety at the Institute for Health Improvement. His work focuses on preventing rehospitalization and other adverse results of poor transition planning. At the CMS he was chief scientist in the Office of Research and later the senior clinical advisor and director of the Quality Improvement Organization program in the Office of Clinical Standards and Quality. He retired his post as Assistant Surgeon General. Jencks is frequently cited by HF clinicians and physicians in discussions of the HF readmission milieu. Jencks et al. (2009) proposed that if hospitals are doing something about the transition discharge processes in a collaborative manner it is a good thing.

Riegel, Lee, and Sochalski (2010) developed an instrument that would describe disease management (DM) programs for heart failure. Criteria were taken from the AHA taxonomy of DM and scored to allow the description of intensity and complexity of the domains of HF DM programs. In 12 programs, the HF Disease Management Scoring Instrument (HF-DMSI) had the most variability in areas of delivery personnel and method of communication (Riegel et al., 2010). This evaluation instrument informs and explains whether inconsistent outcomes from HF DM programs are due to the interventions undertaken or to their insufficient use. Methods of communication within 
interventions are vitally important when approaching self-care with HF patients (Lee, Moser, Lennie, \& Riegel, 2009; Moser \& Watkins, 2008).

In July of 2009 Medicare began public reporting of hospital RSRRs of fee-forservice patients discharged after HF from all acute care U.S. nonfederal hospitals (Ross et al., 2010). The alarming fact is that in recent years there has been no change in the national mean for RSRRs. This indicates there has been improvement in neither readmission rates nor hospital variation rates over this time period (Ross et al., 2010).

In 2011 the Congressional Research Service identified the reductions in hospital readmission as a source that would reduce Medicare spending (Stone \& Hoffman, 2011). On March 23, 2010, President Obama signed into law the comprehensive healthcare reform legislation, as amended by the Health Care and Education Reconciliation Act (Stone \& Hoffman, 2011). This reform was to measure potentially preventable readmission rates. However, the potential would become dependent on the effectiveness of the design and implementation of proposals to reduce readmissions (Stone \& Hoffman, 2011).

Waterworth and Jorgensen (2010) studied the experiences of older patients moving from one phase of HF to another that are described as transition phases. Instead of a specific transition point, these patients illustrated the complexity of transitioning from independence to dependence while approaching the end of life. The authors found that the new transition beginnings of these patients could be a framework about hope from the start that could minimize fears they would face at the end of life. The syndrome of HF is not often viewed by the public as one related to end of life (Aspinal et al., 2011). For this reason some facilities prefer to use the POS as the Patient Care Outcome Scale instead of the Palliative Care Outcome Scale. Bausewein et al. (2011) 
found that the POS made a considerable contribution to outcome measurement in palliative care as reflected in 44 papers over the past 10 years. The POS is well accepted as an outcome measurement tool in palliative clinical care as well as HF research (Bausewein et al., 2011; Carver et al., 1989; Hearn \& Higginson, 1999).

\section{Evidence-Based Solutions}

The reduction of excessive readmissions in HF is a problem that has gained national attention. Multiple interventions that address this problem are documented in literature (Annema et al., 2009; Balaban et al., 2008; Boutwell et al., 2009; Dedhia et al., 2009; Greenwald et al., 2007; Jack et al., 2009; Klersy, De Silvestri, Gabutti, Regoli, \& Auricchio, 2009; Krumholz et al., 2002; Phillips et al., 2004; Sochalski et al., 2009).

Interventions for improvement of discharge processes are a primary category. The agreement by all contributors was that there needs to be an improvement in the discharge processes of HF patients as they transition to the next care setting (Annema et al., 2009; Balaban et al., 2008; Boutwell et al., 2009; Dedhia et al., 2009; Greenwald et al., 2009; Jack et al., 2009; Phillips et al., 2004).

The IHI's analysis of findings in a literature survey meta-analysis revealed four categories of interventions to reduce rehospitalizations. Categories were enhanced care and support at transitions, improved patient education and self-management support, multidisciplinary team management, and patient-centered care planning at end of life (Boutwell et al., 2009). In a multimethod analysis by Greenwald et al. (2007) components of the hospital discharge process that related to adverse events and readmissions were examined. In 2006 the NQF Consensus Standards Maintenance Committee in 2006 added the hospital DC as one of the safe practices for better 
healthcare. Quality of care practices across major organizations such as the Joint Commission on Accreditation of Hospitals were synchronized providing a road map that satisfies common major purchasing, accredition, and quality of care requirements (Greenwald et al., 2007). Project RED was operationalized into 11 components. The Project RED reengineered discharge process road map was the basis for this Capstone intervention of an acute symptom management tool for patients.

Another discharge intervention in the literature was a toolkit for DC planning (Dedhia et al., 2009). This toolkit had similar swap components to other DC interventions. Core elements were an admission form with geriatric cues for primary care providers, interdisciplinary worksheet to identify barriers to DC, pharmacistphysician collaboration for medication reconciliation, and predischarge planning appointments. 


\section{CHAPTER III \\ PROJECT DESIGN \\ IRB Project Proposal}

\section{Purpose}

The goal of this research was to determine factors influencing worsening symptoms of HF in elder HF patients and to examine POS functional scores following distribution of a HF management tool. Secondary objectives were to improve the quality of life that may result in the reduction of readmissions to the hospital. This research could supplement the literature on HF interventions that contribute to reduction of acute exacerbations of HF and unnecessary hospital readmissions.

Description of Study

The project leader was to directly observe HF patient visits at Pioneer Healthcare LLC. The Director of Pioneer Healthcare recruited 10 HF patients who were participating in follow-up clinic visits post-discharge from the hospital. The patients were given a pamphlet on acute care symptom management while being recruited, then scheduled to return for their next regular clinic visit for the study interview. The study participants were briefed on how to fill out the questionnaire prior to administration.

The project leader worked with Brad Massey, ACNP and Director of Pioneer Healthcare, to determine subjects that fit criteria. Massey purposively selected elder patients aged 65 years or older, diagnosed with HF, New York Heart Association classification Stages III to IV, referred and being seen within 30 days of discharge from the hospital. Massey asked each potential candidate during a clinic visit whether they 
might be willing to participate as a subject. Subjects who met all criteria and voluntarily agreed between April 13, 2012, and June 5, 2012, participated in the study.

The subjects were interviewed and asked to participate in a consent process after explanation by the project leader. The consent process was prior to the interview. Psychometric outcomes were examined with the POS instrument which reflects measurable quality-of-life outcomes at a certain point in time. The POS instrument was distributed to participants, which took about 15 to 30 minutes to complete. One openended question was asked of participants: If any, what have been your main problems in the last 30 days? A probe statement followed: Tell me more about your problems. If needed a third probe question was asked: How does that make you feel? There were no restrictions on activities during questionnaire administration. All aspects of the study were explained to participants.

\section{Benefits}

Few studies have focused on patient-reported functional status and qualitative findings in quality-of-life outcomes for HF patients. The data provided implications about adherence to self-care management and adherence in the HF population, which might guide future research and interventions. The increased knowledge of acute symptom management could give HF patients a higher degree of quality of life with reduced hospital readmissions.

Risks

There were no potential physical, psychological, and/or social risks for participants taking part in this study. The instrument was straightforward with no hidden meanings. Participants were selected based on Capstone Project criteria. 


\section{Confidentiality}

All measures were taken to protect privacy and confidentiality of patient information. No names were placed on instruments. They were numbered to allow for matching of the repeated measures and the various instruments. The master list of names and identification numbers was stored in a locked cabinet accessible only to the project leader. The completed instruments were securely stored in another cabinet which was locked. All data were analyzed as group data. No individual responses were identifiable. At the completion of data analysis, questionnaires were shredded. No alternative procedures were offered to participants if they could not participate in the study.

\section{Participants' Assurance}

Participants were informed that the project had been reviewed by the Institutional Review Board, and they were asked to direct any questions or concerns about rights as a research participant to the Chair of the Institutional Review Board. Participation in this project was completely voluntary, and participants could withdraw from this study at any time without penalty. The POS instrument and the consent form for participants were submitted with the USM IRB proposal.

\section{Project Management Tools}

\section{Milestones}

Activities for this project began in September 2010 as the project leader began to identify a gap in practice by literature review. Activities, citations, and systematic reviews and articles were sourced from September 2010 through December 2011. The topic originally identified was $\mathrm{HF}$ and self-care management related to 30-day readmissions in elder females. As the project unfolded, the population changed to 
include both male and female HF patients aged 65 years and older. From January 2011 through December of 2011, the PICOT question was formulated and researched. The purpose of the study was to explore the patients' own perceptions about their heart failure symptoms and identify themes that contribute to how patients make decisions about their self-care management of acute HF symptoms.

The site identified for the project implementation was Pioneerhealth LLC, a contract affiliation of FGH. In this setting all patients are HF NYHA classification Stages III to IV. The project leader contacted the nurse for the HF physician at FGH to discuss possible clinical hours. The nurse for the HF physician explained that, if the project leader followed the physician, cardiac patients of all types would be seen in the course of a day. Heart failure patients would be seen sporadically. The decision was made to immerse time into HF patients only and follow the ACNP at the clinic. Heart failure patients are referred by physicians to this clinic following discharge from the hospital. Brad Massey, ACNP, was established as the champion for the Capstone Project. Tara Harbart, RN, was another stakeholder who functions as heart failure nurse for FGH, and assisted with the project from August 2011 to July of 2012. She set up the contact for Massey at Pioneerhealth LLC. Harbart invited the project leader to be a member of the HF Task Force that had been formed at FGH for the purpose of reducing HF readmissions. Involvement with this Task Force created opportunities for meeting multiple stakeholders invested in the readmission reduction efforts of HF patients.

Early in the project, contact was made with the 4T telemetry manager at FGH. Howard Nobles invited the project leader to present the gap in practice and suggested intervention to the Triad meeting of case managers, HF nurse, and patient care coordinators on the telemetry floor. The project was presented at that time to address a 
gap in clinical practice as evidenced by lack of self-care management in HF patients, which might have resulted from discharge teaching strategies. Examples of improvement in other agencies were presented where the discharge teaching time was lengthened to one hour of face-to-face teaching with the patient (Boutwell \& Hwu, 2009; Hines et al., 2010). The intervention of extending teaching time by registered nurses was suggested to the Triad committee as identified by evidence-based literature. The suggestion was met with resistance by the floor manager due to time constraints of floor duty nurses which was a barrier for the project. Following this meeting the intervention was modified to a teaching tool for HF patients in the clinic setting, instead of asking hospital nurses to teach with an extended timeframe. The present focus at the HF clinic is face-to-face teaching by the nurse practitioner with HF patients. This setting provides an improved setting for patient teaching.

During the Fall of 2011 the needs assessment began, as contacts were made during committee meetings and individual meetings with stakeholders. Clinical hours focused on immersion with the HF patient population and observation of the self-care management directly taught to patients. A second clinical site was established with the FGH home health telehealth program. Telehealth installation visits are made by home health nurses. These nurses teach self-management with the assistance of telehealth monitors that convey blood pressure, oxygen saturation, heart rate, and patient weight to the office. Each day nurses personally call the patients whose findings exceed normal parameters. Needs assessment continued while observing cardiac teaching and patient responses to teaching during home health telehealth monitor installations in the home setting. 
A barrier that was identified in February 2012 was that the reduction of readmissions could not be an outcome for the project. The readmission rates are published annually. Time would not allow this to be a viable outcome. Literature also suggested that biomarkers such as systolic blood pressure and ejection fraction or other significant outcomes be utilized instead of readmission rates. These rates are a longterm outcome and could not be realized within the timeframe of this Capstone Project. Systolic blood pressure and ejection fraction biomarkers were collected during the study as viable outcomes for short-term research.

\section{Design of Study}

After considering barriers, the plan was established in the summer of 2011 to implement a mixed design study with HF patients that would demonstrate the efficacy of improved acute care self-management strategies in the elder HF population. Prior to implementation of the project study, an intervention tool was adapted and further developed for dissemination. The design of the study was a mixed method, qualitative and quantitative study. Grounded theory analysis of qualitative responses of patient perceptions of problems was planned (Glaser \& Strauss, 1967). Qualitative responses were analyzed through the lens of Lazarus and Folkman's transtheoretical model of stress (Lazarus et al., 1985). Quantitatively, the psychometric quality-of-life outcome measures from the POS were planned to provide empirical data from staff, caregiver, and patient-completed questionnaires with descriptive statistics. Demographic data and biomarkers were collected along with participant interviews.

The IRB proposal to FGH was developed in March 2012. The project leader presented the IRB proposal permission and approval to the IRB Committee at FGH in April 2012. The FGH chair of this committee presented the IRB proposal and 
supporting documents to the Nurse Practice Council with approval granted by the FGH organization (see Appendix D). Oral examination defense commenced on April 30, 2012. The IRB approval request form was submitted to The University of Southern Mississippi and received with Exempt Approval (see Appendix E).

Implementation of the project began following IRB approval from USM in May of 2012. Data collection was planned from May to July of 2012. Analysis of findings and evaluation of the project followed implementation from August to September 2012. Planning Timeline and Budget

The planning timeline for the Capstone Project is summarized in Table 7. The budget for the project was described previously with a cost-benefit analysis. No expenses were incurred for the patient or the clinic. Heart failure interventions are not cost-effective, and interventions to reduce excessive readmissions were implemented to reduce readmission rates to less than national averages of 24.8\% (USDHHS, 2011). The project leader absorbed expenses of paper, pencils, and recordings.

Table 7

Timeline for Capstone Project

\begin{tabular}{llllllll}
\hline & Fall & Spring & Summer & Fall & Spring & Summer & Fall \\
& 2010 & 2011 & 2011 & 2011 & 2012 & 2012 & 2012 \\
\hline $\begin{array}{l}\text { Literature } \\
\text { review }\end{array}$ & Sept. & -- & -- & -- & -- & Jan. & \\
PICOT & Jan. -- & -- & Dec. & & \\
$\begin{array}{l}\text { Site contacts, } \\
\text { needs analysis }\end{array}$ & & & & Oct. -- & Mar. & \\
& & & & & & \\
\end{tabular}


Table 7 (continued).

\begin{tabular}{|c|c|c|c|c|c|c|c|}
\hline & $\begin{array}{l}\text { Fall } \\
2010\end{array}$ & $\begin{array}{l}\text { Spring } \\
2011\end{array}$ & $\begin{array}{l}\text { Summer } \\
2011\end{array}$ & $\begin{array}{l}\text { Fall } \\
2011\end{array}$ & $\begin{array}{l}\text { Spring } \\
2012\end{array}$ & $\begin{array}{l}\text { Summer } \\
2012\end{array}$ & $\begin{array}{l}\text { Fall } \\
2012\end{array}$ \\
\hline $\begin{array}{l}\text { Proposal } \\
\text { defense }\end{array}$ & & & \multicolumn{5}{|c|}{ Feb.- Apr. } \\
\hline IRB process & & & \multicolumn{5}{|c|}{ Mar.-May } \\
\hline Collect data & & & & & \multicolumn{3}{|c|}{ June-July } \\
\hline Defend & & & & & & & Sept. \\
\hline $\begin{array}{l}\text { Evaluate, } \\
\text { disseminate }\end{array}$ & & & & & & Aug. -- & Nov. \\
\hline
\end{tabular}

\section{Evaluation Plan}

\section{Planning and Evaluation}

Evidence-based practice for the DNP project was applied broadly and did not have a defined research question (Zaccagnini \& White, 2011). The evaluation for this project was a mix of both qualitative and quantitative data. These statistical methods and analyses were planned to be useful for the project, but the evaluation was different from that of a specific research project. The evaluation was planned to provide accountability to the stakeholders and demonstrate effectiveness in the HF population. The tools, methods, and resources for this Capstone Project are delineated in the Logic Model for Heart Failure Patients (see Appendix F).

Qualitative evaluation of data was planned to meet the primary aim of the project, which was determining factors influence worsening of symptoms in a sample of elder heart failure patients. The main themes of heart failure perceptions from 
participants' perspectives were to be coded and determined by two expert reviewers. The research question was to qualitatively explore HF patient perceptions of their worst problems to determine factors that actually influence an exacerbation of heart failure.

The two reviewers planned to extract data from each of the study participants, their caregivers, and staff based on responses to the POS instrument. Question 11 was administered on the survey, as well as audibly recorded. This qualitative data were to provide contextual meaning to the quantitative data for the project. Qualitative data would also provide meaning to the stakeholders, the organization, and the HF patients. Transcription was planned immediately following each interview. The reviewers planned to analyze codes and themes guided by Glaser and Straus's grounded theory model (cited in Burns \& Grove, 2009; Zaccagnini \& White, 2011). Grounded theory was applicable for both the qualitative and quantitative components of the study (Glaser $\&$ Strauss, 2009). This methodology is general about symptoms and conditions and assisted the reviewers in understanding the situations in which patients found themselves when suffering from conditions about which very little is known. In heart failure, only the patient knows feelings and perceptions of the experienced symptoms. Words from the patients themselves enabled reviewers to identify the descriptions of patient symptoms (profile scores) and how patients move to possible understandings of the processes and adapt their behavior (Burns \& Grove, 2009).

Quantitative descriptive statistical analyses were planned to address the second objective of analyzing the psychometric outcome variables of functional status. Profile data scores for each participant were to be analyzed with ANOVA. The scores would reflect the patient's own ranking of quality of life. Comparisons of the patient, caregiver, and staff scores were to be generated. Generalizations and implications were 
to be drawn from these analyses. Paired $t$ tests would compare individual questions to examine differences in responses.

Several outcome objectives were planned to meet the primary goal of determining factors that influence worsening symptoms of HF syndrome. The project leader met with the clinical site champion to observe teaching strategies and patient responses prior to implementation of the project. During this time observation of the context and content of teaching could give meaning to data collected. The project leader also observed telehealth installations in the homes of HF patients with a registered nurse, which would provide contextual meaning to how patients respond to cardiac teaching in their home environments.

A second outcome objective was distribution of the intervention tool by the site champion. He was instructed to ask participants to be involved in the study with a written script and give them an appointment for the date and time of the interview. He was to purposively select Stages III and IV NYHA patients aged 65 years and older.

A third outcome in meeting the primary goal of examining patient perceptions was to be met by actual implementation of the survey in the clinical setting with recorded interviews and administration of the POS instrument. The purpose of the research was to qualitatively explore HF patient perceptions of their worst problems to determine factors influencing worsening symptoms of HF. Two expert reviewers reviewed qualitative findings and recorded codes and themes to identify a possible emerging theory. The patient, caregiver, and staff completed separate questionnaires of the POS. These three components were compared quantitatively to analyze patient responses of their quality-of-life status at their return clinic visit. The project leader was to collect the three data sets of psychometric functional status by measurement of 
the 10 quality-of-life outcome variables. These QOL outcome variables with a global summed score from the POS instrument at a point in time might provide information for the researcher to draw conclusions about self-care management and adherence patterns in the sample HF population.

In addition to the survey, the collecting of biomarkers of ejection fraction, systolic blood pressure, daily weight, and chart reviews by the ACNP provided quantitative data. Evidence-based literature demonstrates that measurable outcomes and biomarkers for HF that include patient ejection fraction and systolic blood pressure $\leq 100 \mathrm{mmHg}$ are viewed as more reliable indicators than number of times the patient is readmitted to the hospital (Collins et al., 2009).

The use of the POS instrument outcome measures were related to baselines for biomarkers and levels of pain or distress. Measures also assessed patient symptoms and patient or family needs or problems. The effect of the interventions was evaluated with analysis of patient, caregiver, and staff profile scores of patient problems related to their heart failure status. The outcomes were hoped to lead to changes for improved quality of life or decreased anxiety (Bausewein et al., 2012).

The long-term goal of seeing a reduction in excessive HF readmissions compared to the national average was not within the timeframe of this project. Longterm objectives could be met over a longer period of time by trending statistics from US DHHS (2011) to compare national HF 30-day readmission rates with previous rates. A second long-term objective of seeing an improvement of HCAHPS scores for medication teaching, which are a reflection of patient satisfaction with their healthcare in the hospital setting, also did not fit within the timeframe of this project. 
Evaluation and dissemination phase objectives included collaboration with the project champion and hospital IRB Chair to provide the findings of the study. Reports of findings were presented to FGH's Research Committee as scheduled by the FGH IRB Chair upon completion of the Capstone Project.

\section{Logic Model}

Logic model development for the project depicts inputs and outputs with changes in health, reflecting quality-of-life outcomes (Bausewein et al., 2012; Hearn \& Higginson, 1999). Logic models are valuable for adding graphic illustrations of nursing theory and directing an action plan (Ellerman, Kataoka-Yahiro, \& Wong, 2005). Sound nursing judgment develops from acquiring a specific knowledge base, experience, critical thinking competencies, and standards in nursing. Logic models take nursing processes of linear problem-solving activities toward a more complex and multidimensional view of nursing problems and issues. Logic models assist in promoting scientific hypothesizing and focus on the context of patients' perspective of human health (Ellerman et al., 2005). Critical thinking assists nurses in the identification of desired nursing actions and patient outcomes (Ellerman et al., 2005). The logic model is a schematic representation of inputs, processes, outputs, and goals. Inputs are the resources that were required to implement and evaluate the project. The process describes how the resources were utilized or what was done with them. Outputs or throughputs describe the intended immediate results of work performed for the project. Changes in healthcare explain the goals or desired impact for clients participating in the study. For short-term outcomes, the project leader observed patients on repeat clinic visits and how they responded to prior instructions by adherence to 
standard practices. Long-term outcomes would reflect a change in their behavior or motivation.

With inputs established, the process and outputs were hoped to result in qualityof-life changes for the patients. It was expected that they would become more acutely aware of actions to take if their HF status exacerbated. Improvement in quality-of-life parameters were to be evidenced by biomarkers of ejection fraction and systolic blood pressure readings. They were also expected to report a lessening of fluid retention as evidenced by consistent daily weights, normal sodium levels, and less shortness of breath. It was anticipated that they would possess verbalization of improved decision making upon return visits to the congestive heart failure clinic. The follow-up outcomes such as improved biomarkers were not originally planned to be measured as part of this study. Their biomarkers were recorded during the Project interview.

Statistical findings were to be delineated empirically. Reported measures might be a comparison of individual measures such as pain and anxiety management using two items of the POS. Generally, for research, the POS data are presented in a summed or aggregate manner. Patients and organizations would not be identified or identifiable. The findings would be published for wide dissemination (Bausewein et al., 2012). Implementation

Review of Project

Following IRB approval by FGH's Research Committee and Nurse Practice Council, the proposal was submitted to The University of Southern Mississippi and approved in May 2012. At this time, all components of the project were reviewed for accuracy. Several minor revisions were made to the goals and objectives to more clearly identify how outcomes would be met. An outcome that was changed was to 
forego obtaining a reduction of hospital readmissions. Literature revealed this was not a reliable outcome due to length of time necessary to retrieve data on readmission rates (Collins et al., 2009). The work plan was appropriate for the problem identified in the needs assessment. The project leader collaborated with the site champion to review processes for selecting participants, explaining their role, disseminating the tool, and setting appointment dates for return clinic visits. A date was set to implement the study. Stakeholders at the hospital were notified of beginning dates.

\section{Threats and Barriers}

Predicted barriers were that the sample of patients purposively selected would not contribute substantively to the purpose of the study. If patients were too healthy, end-stage heart failure contextual information might be missing. Also, the age of the sample might be important. The project leader allowed the site champion to make these decisions with instructions to select patients aged 65 years or older and with Stages III or IV NYHA heart failure. At closure of the study, there were $80 \%$ Stage III participants and 20\% Stage IV. This fit the project leader's request for Stage III or Stage IV patients but was predicted to affect outcomes.

The fear that interest was waning over time by major project stakeholders threatened the project. The site champion appeared very positive and cooperative throughout the process and consented to implementing the study. It was agreed that the sample would be assigned an appointment time for all those consenting to complete the survey. Time did not permit a longer period for selecting patients other than those coming to the clinic on a regular basis which affected the age range of sample population. The patient sample was defined by who came in during the allotted project timeframe. 
Another barrier was time limitation. Due to the timeframe to complete the project, long-term outcomes could not be measured. The study would be a study at one point in time instead of multiple surveys to the same patients over a period of time, such as every 30 days for 6 months. In spite of barriers and threats, the project leader believed the information that would be collected at a point in time would be valuable in meeting project outcomes.

During the implementation phase of the project, the project leader collaborated frequently with the site champion to organize appointments and dates to perform interviews when the patient, his or her caregiver, the staff champion, and the project leader could all be present. The progress of the study met proposed timelines. Two patients did not attend their clinic appointments, so two other patients were selected to take part in the study.

\section{Project Closure}

At the completion of the study, the project leader thanked the site champion and stated that contact would be renewed when the study was analyzed and the results were evaluated. Plans were made for the project leader to meet with the site champion, the hospital heart failure nurse, and the hospital Research Committee to share results of the study.

Data Analysis and Results

\section{Quantitative}

An ANOVA was computed comparing the patient, caregiver, and staff perspectives of Questions 1 to 10 on the Palliative Care Outcome Scale instrument (Bausewein et al., 2011; Hearn \& Higginson, 1999). The first analysis computed was comparisons of the patient, caregiver, and staff scores $(N=7)$. Three caregivers were 
missing, so only 7 respondents could be compared instead of 10 . When looking at these means, 10 questions were totaled. Each question ranged from zero to four, so scores for comparison could range from zero to a total score of 40. The instrument is scored so that negative responses receive the highest scores. Patients scoring symptoms as worse (as opposed to better) generated higher scores (Hearn \& Higginson, 1999).

Overall, the patient scores appeared low. Means and standard deviations of patients $(M=11.86 \pm 5.08)$, staff $(M=8.86 \pm 3.34)$, and caregiver $(M=12.14 \pm 7.69)$ did not differ significantly in any of the three groups, $F(2,12)=1.223, p=0.329$. Patient scores were about 12 out of 40, staff around 9, and caregivers about 12 out of 40. The patients did not appear to be marking some of the overwhelming problems; so, the patient, staff, and caregiver respondents were not rating them with the overwhelming problems such as pain and other symptoms. The total mean summary scores appeared low for this sample.

Although the numbers reported appeared different, they appeared different in the way that would be expected in that the staff said they had lower symptom ratings, the patients said they had a little more, and the caregiver said that they really had a lot. Even these numbers were not significantly different. There was no significance and scores were not statistically different. The sample size was too small with only 7 to achieve significance. This may not be a complete analysis since 3 patients did not have caregivers.

Since 3 caregivers were missing, an ANOVA was run comparing patient responses to staff responses only of Questions 1 through 10. Without caregivers, this gave a sample of $N=10$. With this comparison, it was obvious that the staff were rating these questions much lower than the patient. This was statistically significant in 
that the patient was experiencing these symptoms $(M=11.50 \pm 4.55)$ much more than the staff $(M=7.70 \pm 3.89)$ was reporting, $F(1,9)=6.644, p=.030$. The patient responses were much higher than staff responses. The staff were not catching all the worsening symptoms that patients were experiencing. Reasons for this may raise questions for further research.

With closer analysis of three of the 10 questions and comparing only patient with staff, they are significantly different. Rather than the total score, looking closer at each individual question raised interest. There was a difference on three questions, 1, 2, and 8 , respectively. Of these, in every case the patient score was much higher than the staff score. A $t$ test was calculated comparing the individual 10 questions of each participant. Significant differences were found on Question 1 for pain, $t(9)=3.161, p=$ 0.012, Question 2 for other symptoms such as nausea, $t(9)=2.57, p=0.030$, and Question 8 for feeling good about self, $t(9)=2.333, p=0.045$, which is coded so the higher the score, the more they do not feel good about themselves. So when staff said they were feeling good about themselves and the patient said they were not, one needs to examine the coding. It is coded for the most points being that they do not feel good about themselves. The higher score reveals a more negative view of the perception, worse being a higher number. From this analysis it was evident that the staff were not catching all the pain or other symptoms such as nausea and not getting a realistic view of the patient from this sample. This was significant, but this is only for the sample of 10 participants in this particular study.

\section{Qualitative}

Interviews with the subjects were tape-recorded and transcribed verbatim. The transcripts and recordings were analyzed and the categories were discovered empirically 
from the appearance of themes in the patients' descriptions. The unit of analysis was determined by theme rather than by word, sentence, or paragraph in order to code for meaning related to the study purpose. Further reanalysis were refined into four themes.

The first theme was physical symptoms and suffering. This was defined as pain, extreme fatigue, weakness, debilitating tiredness requiring frequent naps, shortness of breath, debilitating weight gain, swelling, fluid on upper lungs or chest, swelling secondary to salt intake, difficulty sleeping due to inability to lie flat, insomnia, having to sleep propped up to breathe, barely breathing on own, dyspnea, no energy, and inability to perform normal activities of daily living.

Care management was the second theme and included formal and informal caregiver roles. These consisted of nurse or physician, incompetent system management, misdiagnosis, absence of information related to diagnosis, the clarification or interpretation of care management, miscommunication, being poorly or wrongfully educated, the absence of nurse role awareness or acknowledgement, absence of home health nurse acknowledgement (they are invisible), and social issues such as isolation or support both formal and informal.

The theme of self-care agency or behaviors encompassed expressions of ability to care for self (activities of daily living), dependency on others, information needed by patients to manage self-care related to competence and self-management of symptoms, compliance, and understanding of disease management. Secondary to these self-care behaviors were practical issues such as hygiene, mobility, fear of not knowing the significance of symptoms and from whom or when to seek care, poor physician access, independence, work, employment or unemployment, caring for family, and essentially carrying out the role of a self-sufficient adult. 
The psychological theme experience was comprised of mood, anxiety, frustration, anger, fear, hopelessness, panic, pessimism about progression of disease, mental anguish related to pain, negative emotional effects from extreme fatigue and difficulty breathing, depression, severity of symptoms and not having the knowledge to take care of self or make appropriate decisions, feelings of worthlessness, family anxiety and disruption of family relationships, stress from stigma of diagnosis, and concern for caregiver.

The thematic analysis summary of qualitative Question 11 is listed in Appendix G. Descriptive excerpts qualify the concepts. A high degree of face validity was achieved in the qualitative question from this approach because the conceptual thematic dimensions were derived from direct observations of the data (interviews). In addition, validation was achieved with a $98 \%$ agreement on themes by expert qualitative researcher, Dr. Karen Saucier Lundy, and project leader, Sharon Vincent. 


\section{CHAPTER IV}

\section{SUMMARY}

The primary purpose of this project was to determine factors that influence the worsening of symptoms of HF in a sample of elder heart failure patients, which could affect readmission to the hospital following discharge. The aim was to develop a wide ranging understanding of the patients' own perceptions about their lived HF experiences compared to caregiver and staff perceptions. The second goal was to analyze psychometric quality-of-life outcome variables of functional status from the patient, caregiver, and staff to draw conclusions about the patient's self-care management following dissemination of an acute care management tool.

The question explored for the study was whether patient education about selfcare management of acute symptoms, compared to usual care for heart failure, reduces hospital readmissions within 30 days of discharge from the hospital. Exploration was in the context of patients making a decision to take action with acute symptoms that might improve their quality of life.

Data were extracted from 10 psychometric outcome variables and one qualitative, open-ended question from the POS (Hearn \& Higginson, 1999). A typical qualitative method for sampling, data collection, analysis and interpretation of data was utilized. The qualitative question used was influenced by the work of Glaser and Strauss who developed the grounded theoretical approach (Glaser \& Strauss, 2009). The goal of this qualitative interview question as an inductive method was to generate descriptive data which provided rich, authentic accounts about heart failure experiences in the patients' own words. This involved qualitative data collection and analysis, whereby themes and concepts emerged or were 'grounded' in the data. According to 
this approach, the generation of themes involves a constant motion of data collection, coding, and analysis. This question was utilized to explore the influencing factors in elder heart failure patients with the intent of examining variables generated directly from the words of the patients, not just those deemed important or valuable by the researcher. Question 11 asked the following: What, if any, have been your main problems in the past 30 days? A second probe, tell me more, and third probe, how does that make you feel or think? were used if needed.

Discussion

\section{Quantitative}

In the first quantitative analysis there were notable differences in scores between patient, caregiver, and staff responses. Overall, the respondents were not highly rating overwhelming symptoms, reflecting a poorer quality of life. What would have been anticipated is that a Stage IV New York Heart Association patient might have reported higher scores with overwhelming problems such as fatigue, shortness of breath, pain, or depression. Literature reveals that elder patients have a problem in their ability to recognize symptoms of worsening HF. Their failure to respond in a timely manner when symptoms occur creates a delay in getting the help they need (Moser \& Watkins, 2008). A Stage IV patient with higher total scores would be associated with more extreme symptoms and severe heart failure syndrome (Bausewein et al., 2012). A chronic heart failure patient with a total score of 20 is considered at moderate level for palliative care (Aspinal et al., 2011). When patients approach higher scores they might be candidates for hospice care (Bausewein et al., 2012), and scores of this sample appeared low. Dyspnea is often the symptom leading to hospital readmission, and this was not reflected by high scores in the sample. 
In a study that determined relative importance of sociodemographics and health perceptions by De Jong, Moser, and Chung (2005), worse NYHA class, higher anxiety, and higher depression predicted worse health-related quality of life. Higher scores of item seven for feeling that life was worthwhile predicted greater symptom burden as well. Scores in this Capstone Study were low overall, and the NYHA class was Stage III in most respondents $(80 \%)$. Sociodemographics and biomarkers are listed in Appendix H. This may have been partly a result of the purposive sampling, but this sample did not reflect overwhelming symptoms that would likely have been apparent in Stage IV patients. This sample of project scores did not reflect a greater symptom burden.

The patients attending the congestive heart failure clinic for this project were receiving thorough instructions from the ACNP. The point in time at which interviews were performed might have reflected a stable condition for many of these participants. The participants had returned to the clinic following initial visits during which they received teaching by the ACNP. Patients were selected during a specified timeframe, which may have narrowed obtaining more Stage IV participants. Elders are a vulnerable population as they face the transitional period of discharge from hospital to home settings. There has been a focus on transitional care for HF elders, and studies have found that readmissions and healthcare costs are reduced with transitional care interventions (Boutwell et al., 2009; Naylor et al., 2004). The evidence base of what works in chronic management programs is not as developed as it should be. Sochalski et al. (2009) reanalyzed data from 10 clinical trials of HF management programs to distinguish how healthcare delivery program methods contribute to patient outcomes. They found that persons enrolled in multidisciplinary teams and in programs that used 
face-to-face communication had significantly fewer readmissions than patients with routine care (Sochalski et al., 2009). In the Boutwell et al. (2009) compendium of 15 promising interventions, the Project RED had a strong focus on transitional methods with 11 specific steps for hospitals to initiate. This was a collaborative, multidisciplinary method to reduce readmissions. The intervention tool for this Capstone Project was based on the Project RED interventions (Boutwell et al., 2009). Many of the 15 Boutwell et al. studies found face-to-face communication and teaching to be important in the transition phase for HF patients. The ACNP at the clinic for these patients spends an hour at each first visit and as much time as needed on subsequent visits to thoroughly explain each patient's cardiac care and medications.

In summary of the quantitative analysis, there were differences in scores of the respondents $(N=7)$ compared to one another. The differences suggested that all three groups of participants were not rating perceptions as overwhelmingly as the scale permitted. Higher scores were expected than those that resulted. Expected differences were noted. Staff said that patients had lower scores of overwhelming symptoms, patients said they had a little more symptoms, and caregivers said they had even a little more overwhelming symptoms, but these were not significant. So these scores of symptom severity were just different, not significant. Secondly, staff were not catching all symptoms that patients were perceiving or reporting. An examination of means and standard deviations revealed that the caregiver had a little more realistic view of what was going on with the patient than the staff. Staff may need to be listening to caregivers more often. The patient score being much higher than staff score suggests that either patients are not reporting symptoms as detailed and realistically as they should, or staff was not picking up on the severity of symptoms reported. When three questions stand 
out that were decidedly different, this again may suggest that staff were not getting a realistic view of what is actually happening with the patient. The global scores generated by summing the scores for each patient provided insight into their overall condition. Summative scores were well below 20, as might have been expected considering NYHA classifications.

\section{Qualitative}

The present research was exploratory and the purpose was to investigate and describe the management of HF in a small sample. Themes and interpretations were limited to the 10 respondents in the study and there was only one qualitative question asked. However, the initial findings in this exploratory study suggest that patients with chronic disease, such as HF, are dissatisfied with their inability to understand the disease and care management as a result of a fragmented and inefficient "nonsystem" of today's "managed care." Nurses were most notably absent in the patient descriptions of their experiences and should be explored further. Nurses who work with these patients could also be included in further studies, comparing the perceptions of nurses and patients as to the prioritization of care. Based on this study, the advanced practice nurse has a critical role to play in managing chronic disease such as heart failure in all aspects of the patient and family's care management.

\section{Limitations}

The project study used a purposive sampling technique. The sample was relatively homogeneous in terms of gender, ethnicity, and biomarkers. Because of the qualitative nature of the project, the sample was small. The quantitative results represented only $N=7$ because the patients did not all have caregivers. Therefore, the results may not be generalizable to all patients with $\mathrm{HF}$. Both qualitative and 
quantitative results highlight the need for improved communication during the discharge and transition process for HF patients.

The main limitation for the quantitative analysis was its small sample size. Secondly, 3 of the 10 respondents did not have caregivers. The numbers had statistical significance with patients scoring higher numbers than staff for symptoms, but this was for the Capstone sample population only.

In considering CMS readmission rate statistics during the needs assessment phase, numbers from 2011 could not be included, as the data were not yet calculated and completed. The most recent numbers used in this project were 2010 figures. The national U.S. figures are completed annually and stay one year behind actual statistics. CMS instituted a policy of using 3 years of discharge data and a minimum of 25 cases to calculate an excess readmission ratio of each applicable condition for each hospital. For FY 2013 the excess readmission ratio from the USDHHS will be based on all discharges occurring during the 3-year period between July 1, 2008, and June 30, 2011.

$$
\text { Implications }
$$

\section{Quantitative}

Evidence suggests that oftentimes if a staff member answers questions for a patient about symptoms, such as pain or anxiety, the severity of the symptoms is underestimated (Bausewein et al., 2012). This trend may have been apparent with the sample of participants and staff, but raises questions used in the current study about the reporting of patient symptoms for future research. Are staff members catching all the cues patients give on assessment? Are patients reporting their symptoms honestly and accurately? Are patients masking severe symptoms to appear adherent to treatment regimens? Do patients want to appear healthier than they are? 
The differences between patient and staff responses may highlight issues for follow-up. The questions that rated highest in differences were pain, other symptoms, and feeling good about themselves. These three areas could be further explored individually. These areas may assist staff in identification of areas for practice development and staff education. Differences may also highlight specific needs for this heart failure population. Dyspnea is a leading cause of hospital readmission, and patients need to be sure to report any breathing difficulties or extreme fatigue to staff.

Healthcare providers need to be familiar with and acutely aware of HFSA heart failure symptoms that alert deteriorating conditions. Acute symptoms were highlighted on the acute care tool that was disseminated. Patients were urged to contact their healthcare provider when any of the HF symptoms occurred, and they were instructed on the distinction of severity between symptoms, such as a 2-lb or 5-lb weight gain. Another question that needs exploration is whether, when patients do in fact contact their providers, the providers are quantifying symptoms for accurate assessment and guidance. Further, end-of-life care application to the HF population is now an optional care modality for HF syndrome (Lorenz et al., 2008). Heart failure patients who are NYHA Stage IV are beginning to face the transition from HF to death as they make choices of whether to begin hospice care. They need to be heard and be provided with the guidance to improve their self-management skills.

\section{Qualitative}

Interpretation of results focused on the themes and concepts that emerged from patient perceptions of their HF experiences. The transactional model of stress (Lazarus et al., 1985) was utilized as a lens to guide the review of concepts in a study by Yu et al. (2008) as they examined 14 published studies about coping strategies of persons living 
with congestive heart failure. Coping with symptoms of HF comes about as the patient cognitively appraises their experience and reappraises the stressful event until adaptation occurs (Lazarus et al., 1985; Rice, 2000). Conceptual data were integrated into meaningful domains by the reveiwers of this Capstone Project while listening to firsthand accounts of patients who were living with the disease. While not all qualitative studies use a theoretical model, the transactional model of stress was a good fit for a study related to living with and adapting to HF syndrome symptoms.

The project outcomes reflected how people live with their HF disease. It gives a greater depiction of the illness experience of this vulnerable population, especially in terms of their coping methods and real-life situations. Literature has suggested that HF is a debilitating and distressing condition, which can lead to many unfavorable physical and psychosocial consequences. Concerns over living with uncertainty and possible death are relevant to HF patients, and their overall feelings of being overwhelmed are repeated in quantitative studies and qualitative studies about patients living with HF (Heo, Lennie, Okoli, \& Moser, 2009; Jeon, Kraus, Jowsey, \& Glasgow, 2010; Jovicic et al., 2006; Rodriguez, Appelt, Switzer, Sonel, \& Arnold, 2008; Waterworth \& Jorgensen, 2010; Yu et al., 2008).

In this project, desperation and frustration were noted in the spouse of one patient as he searched for information about his wife's poor health. Patients with the diagnosis of HF must realize that this is associated with a decline in functional status and is associated with a decreased quality of life (Rodriguez et al., 2008). Heart failure is a leading cause of hospitalization, and unless healthcare providers can give patients an equal amount of information about the progression of the disease and positive steps to take to manage HF, the patients will likely feel overwhelmed and threatened 
psychosocially. Appropriate and effective provider communication, information giving, and support are crucial to management of HF (Rodriguez et al., 2008). Good communication diminishes stress. Several of the Capstone study participants stated that in learning from the ACNP at the clinic, it was the first time they had been given faceto-face teaching information about HF management such as the intervention tool and self-management strategies. Evidence from the literature demonstrates that clinical outcomes are improved with discharge patient education, and patients need enhanced communication with more information about their medical conditions and prognoses (Koelling et al., 2005; Rodriguez et al., 2008).

\section{Suggestions for Future Directions}

Even though the study had a small sample, it is recommended the study be replicated with a larger sample and participants who do in fact have caregivers. A larger sample with more diverse respondents is recommended, along with more frequent interviews over time such as every 30 days for 3 months and increased reliability by adding additional data collection such as a self-written, daily journal addressing these themes. In the Project sample of findings, the nurse presence appears to be missing. Patients answered questions, but the nurse was decidedly absent from their comments. The themes of fragmented healthcare systems and poor access to care were outcomes of the qualitative exploration. In the future, nurses also need to look at patient satisfaction and, perhaps, patients would stay out of the hospital (Hines et al., 2010; Jack et al., 2009). Problems to be researched in the future are methods that healthcare providers use to assess patient symptoms, the reporting of symptoms by patients themselves as well as their caregivers, and whether patients report their symptoms accurately. 
It is documented that patients who are enrolled in programs using a collaborative approach with multidisciplinary teams and in programs using face-to-face communication have significantly fewer hospital readmissions than routine care patients (Sochalski et al., 2009). The 11 steps recommended by Project RED (Boutwell et al., 2009) demonstrate the need for clear and concise steps during transition phases to minimize the critical window of clinical errors that contribute to readmissions in the first 2 weeks following hospital discharge. This project was based on Project RED's steps for improving the discharge transitional process. Hospital administrators, policymakers, and health plan administrators can use these guidelines to build effective program initiatives and policies for this chronic health condition. Reduction of reimbursement by CMS has begun, and insurers may follow suit. Hospitals and other organizations and agencies need to continue to maintain high standards for HF management. Gaps still remain in healthcare for this vulnerable population.

\section{Summary and Conclusions}

The primary and secondary objectives for the project were met. Exploring and determining factors that might influence an exacerbation of heart failure in the sample of HF patients gave rich and informative data for further research and evaluation. Even though the sample was small, the significance of what the patients were saying through their own evaluation of psychosocial variables reveals several problems. The collaborative and multidisciplinary approach in managing heart failure is needed with a high level of performance by every healthcare provider.

Further research needs to address assessments at all healthcare provider levels with intent listening skills for the extreme debilitating symptoms that accompany HF. A new definition of tiredness or fatigue might be explored for the NYHA Stages III and 
IV population. The three variables of significance for this study were pain, other symptoms, and if the patients felt good about themselves. Even though a small sample, these three areas continue to demand exploration. This study should be replicated with a larger sample and more diverse participants and results compared.

Plans for Dissemination

Following defense and submission of the Capstone Project, the findings will be presented orally to the research committee and champion at Forrest General Hospital. Written dissemination is planned following oral reports in the form of published work of the findings in a peer reviewed journal. An executive summary will be compiled for dissemination to small audiences. Long-term plans are being made to publish related articles in a peer-reviewed journal about effective management of heart failure. 


\section{APPENDIX A}

\section{INTERVENTION TOOL: HEART FAILURE ACTION PLAN}

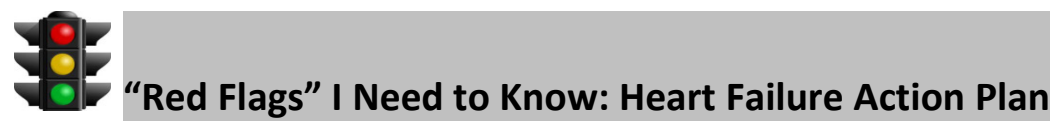

How to use your Action Plan: This Action Plan is a guide to help you manage the symptoms of heart failure. You and your healthcare provider should complete this plan together. The three colors or "zones": green, yellow and red help you decide what to do.

\begin{tabular}{|c|c|}
\hline $\begin{array}{l}\text { Green: means you are doing well. Symptoms: } \\
\text { stable. } \\
\text { - No shortness of breath or you are at your baseline. } \\
\text { - Your weight is stable. } \\
\text { - You have little or no swelling or are at your baseline. } \\
\text { - You are able to maintain your usual activity level. } \\
\text { - You are not having chest pain. }\end{array}$ & $\begin{array}{l}\text { Action: Continue current } \\
\text { medications, diet and } \\
\text { activities. } \\
\text { Weigh daily. } \\
\text { Limit fluids to } 2 \text { liters per day. } \\
\text { Limit sodium to } 2000 \text { mg per day }\end{array}$ \\
\hline $\begin{array}{l}\text { Yellow: means CAUTION. Symptoms indicate } \\
\text { that you may need to talk to your doctor. } \\
\text { - Increased shortness of breath not related to activity. } \\
\text { - } \quad \text { Trouble sleeping; using more pillows to breathe easier. } \\
\text { - } \quad \text { Sudden weight gain of _2 pounds in one day or_5_or } \\
\text { more pounds in one week. } \\
\text { - Increased swelling of abdomen, feet, legs or ankles. } \\
\text { - } \quad \text { Decreased energy level, feeling very tired. } \\
\text { Other symptoms. }\end{array}$ & $\begin{array}{l}\text { Action: Continue yellow } \\
\text { zone treatment plan. } \\
\text { Medications } \\
\text { Instructions: } \\
\text { If you gain } 2 \text { pounds in a day, } \\
\text { take an extra diuretic dose. } \\
\text { Watch salt intake. }\end{array}$ \\
\hline $\begin{array}{l}\text { Red: means you may need help immediately!! } \\
\text { - } \quad \text { Symptoms are very unstable. } \\
\text { - } \text { Nou will need to be evaluated by a healthcare provider } \\
\text { symptoms improve. } \\
\text { - Very hard to breathe, even at rest. } \\
\text { - Weight increase of } 4 \text { or more pounds in one day. } \\
\text { - Wheezing, chest pain or chest tightness at rest. } \\
\text { - Severe weakness, dizziness or fatigue. }\end{array}$ & $\begin{array}{l}\text { Action: CALL YOUR healthcar } \\
\text { provider. } \\
\text { This is a medical emergency. } \\
\text { If appropriate, call } 911 \text { ! } \\
\text { Do not try to treat this yourself } \\
\text { or wait to see if symptoms } \\
\text { improve. Healthcare provider } \\
\text { telephone: }\end{array}$ \\
\hline
\end{tabular}


Name:

Date

Baselines:

These help us track symptoms and recognize changes that are normal or not normal.

Weight:

Current weight pounds. Dry weight pounds (your weight when you do not have swelling).

Swelling:

When and where you notice swelling on a usual day?

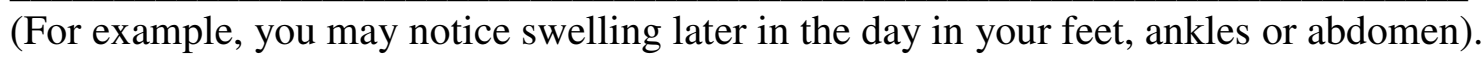

Shortness of Breath: Can be at rest or with activities. How far can you walk or climb stairs or perform an activity before you notice being short of breath?

Fatigue:

Can mean having less energy, needing to take a nap at a certain time of day, or can occur with exertion like walking or climbing stairs. I notice fatigue when

\section{Current Medications:}

My healthcare provider's name and phone number:

(Adapted from Health Net Federal Services printable resources, www.hnfs.com). 


\section{APPENDIX B}

STAGES OF HEART FAILURE

Stage Description

A Patients at high risk for HF but without structural heart disease or symptoms of HF (e.g., patients with hypertension, atherosclerotic disease, diabetes, obesity, and metabolic syndrome or patients using cardiotoxins or with a family history of cardiomyopathy). Such patients have no identified structural or functional abnormalities of the pericardium, myocardium, or cardiac valves and have never shown signs or symptoms of HF.

B Patients who have developed structural heart disease that is strongly associated with the development of HF (e.g., previous myocardial infarction, left ventricular remodeling including left ventricular hypertrophy and low EF, or asymptomatic valvular disease) but without signs or symptoms of HF.

C Patients with structural disease who have current or prior symptoms of HF (e.g., known structural heart disease and shortness of breath and fatigue, reduced exercise tolerance).

D Patients with refractory HF requiring specialized interventions (e.g., marked symptoms of HF at rest despite maximal medical therapy-those who are recurrently hospitalized or cannot be safely discharged from the hospital without specialized interventions).

Note. Four stages involved in the development of the HF syndrome emphasizing both the development and progression of the disease (Hunt et al., 2009; Jessup et al., 2009). 


\section{APPENDIX C}

ILLUSTRATIVE SYSTEM VARIABLES FOR THE STRESS RUBRIC

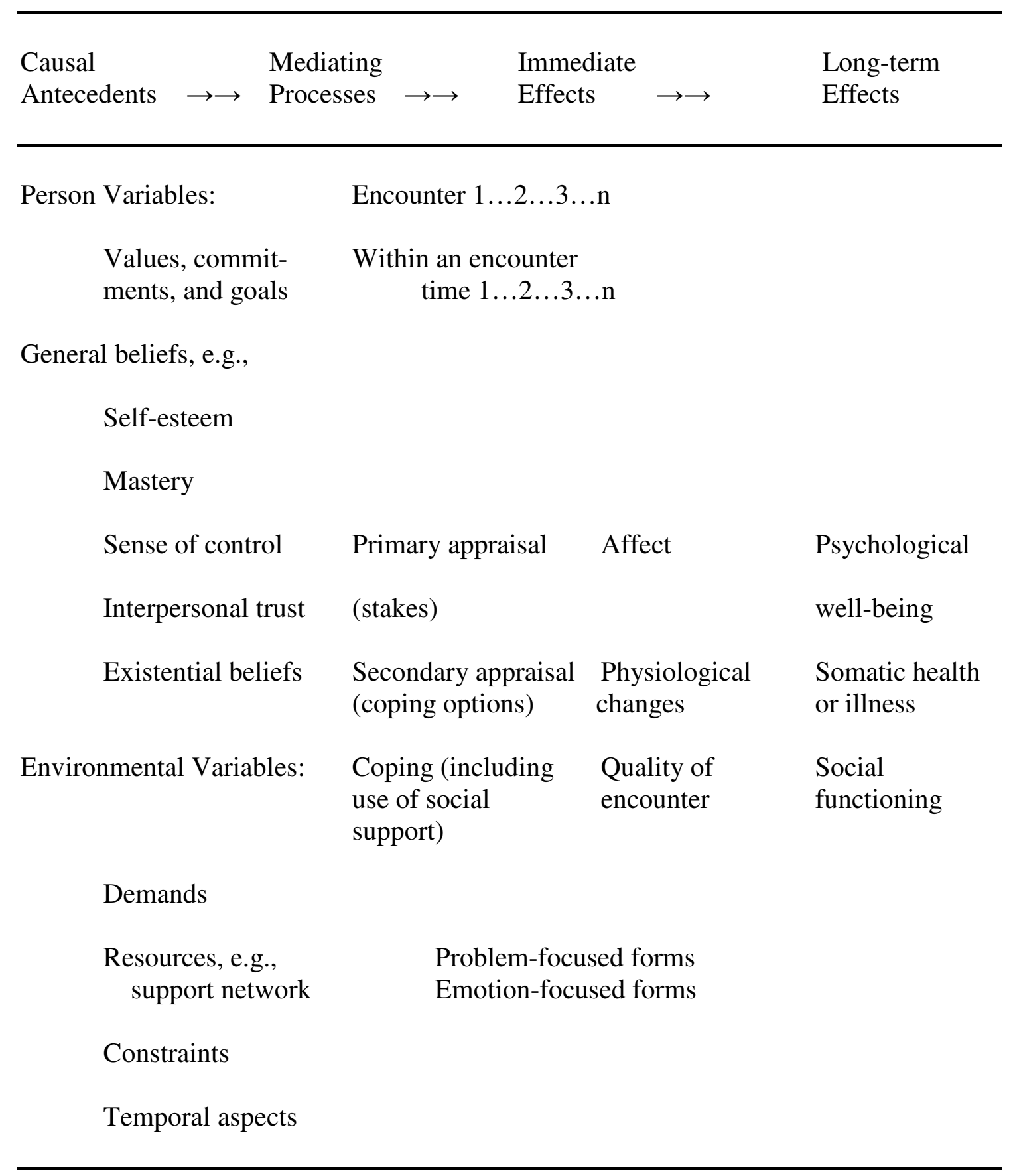

Note. Although not shown here, the model is recursive. Also, noted were the parallelism between shortand long-term effects (as cited in Lazarus et al., 1985). 


\title{
APPENDIX D
}

\section{FORREST GENERAL HOSPITAL'S LETTER OF AGREEMENT}

\section{(45) ForrestGeneral}

\author{
Forrest General Hospital \\ Patient Care Services-Research Committee \\ RESEARCH PROPOSAL LETTER OF AGREEMENT
}

DATE: April 26, 2012

TO: $\quad$ Researcher(s): Sharon Vincent, MSN, RN, DNP Student

FROM: Research Committee

RE: $\quad$ Proposed project/study entitled: Exploration of Self Care Following Distribution of

Acute Management Tool for Elder Heart Failure Patients in Clinic Setting

On April 17, 2012 your research project/study proposal was approved by the Nurse Practice Council to be conducted within Patient Care Services at Forrest General Hospital (FGH). You are free to proceed with your project/study within the following guidelines:

- Data Collection Period: April 2012 - July 2012.

- Modify title of outcome scales to exclude term, "Palliative Care"

- Inform Research Chair when data collection initiated and when completed (via e-mail)

- Provide results of study to committee (may provide presentation to committee or written documentation/summary of findings)

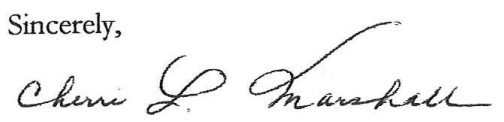

Cherri L. Marshall, RN, MS

Chair, FGH Nursing Research Committee

cmarshall@,forrestgeneral.com

601.288 .8252

P.O. Box 16389 - Hattiesburg, MS 39404-6389

6051 Highway 49 - Hattiesburg, MS 39401-7243

(601) 288-7000 • www.forrestgeneral.com 


\title{
APPENDIX E
}

\author{
APPROVAL OF THE UNIVERSITY OF SOUTHERN
}

MISSISSIPPI INSTITUTIONAL REVIEW BOARD

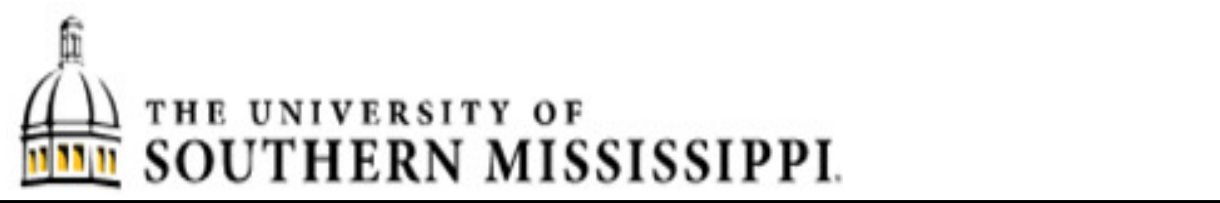

INSTITUTIONAL REVIEW BOARD

118 College Drive \#5147 I Hattiesburg, MS 39406-0001

Phone: 601.266.6820 | Fax: 601.266.4377 I www.usm.edu/irb

\section{NOTICE OF COMMITTEE ACTION}

The project has been reviewed by The University of Southern Mississippi Institutional Review Board in accordance with Federal Drug Administration regulations (21 CFR 26, 111), Department of Health and Human Services (45

CFR Part 46), and university guidelines to ensure adherence to the following criteria:

The risks to subjects are minimized.

The risks to subjects are reasonable in relation to the anticipated benefits. The selection of subjects is equitable.

Informed consent is adequate and appropriately documented.

Where appropriate, the research plan makes adequate provisions for monitoring the data collected to ensure the safety of the subjects.

Where appropriate, there are adequate provisions to protect the privacy of subjects and to maintain the confidentiality of all data.

Appropriate additional safeguards have been included to protect vulnerable subjects.

Any unanticipated, serious, or continuing problems encountered regarding risks to subjects must be reported immediately, but not later than 10 days following the event. This should be reported to the IRB Office via the "Adverse Effect Report Form".

If approved, the maximum period of approval is limited to twelve months.

Projects that exceed this period must submit an application for renewal or continuation.

PROTOCOL NUMBER: 12050801

PROJECT TITLE: Exploration of Self Care Following Distribution of Acute Management Tool for Elder Heart Failure Patients in Clinic Setting

PROJECT TYPE: New Project

RESEARCHER/S: Sharon Vincent

COLLEGE/DIVISION: College of Health

DEPARTMENT: School of Nursing

FUNDING AGENCY: N/A

IRB COMMITTEE ACTION: Exempt Approval

PERIOD OF PROJECT APPROVAL: 05/09/2012 to 05/08/2013

Lawrence A. Hosman, Ph.D. Institutional

Review Board Chair 


\section{APPENDIX F}

LOGIC MODEL FOR HEART FAILURE PATIENTS

INPUTS: $\quad \rightarrow \rightarrow$ PROCESS: $\rightarrow \rightarrow$ OUTPUTS: $\rightarrow \rightarrow$ CHANGES IN

Which resources are required?
How are resources used?
Productivity or throughput
HEALTH OR QOL:

Changes attributable to health care

\begin{tabular}{|c|c|c|c|}
\hline $\begin{array}{l}\text { ACNP, Clinic } \\
\text { office, } \\
\text { telephone, } \\
\text { computer }\end{array}$ & $\begin{array}{l}\text { PET Process: } \\
\text { Practice } \\
\text { question, } \\
\text { Evidence, and } \\
\text { Translation }\end{array}$ & POS Survey data & $\begin{array}{l}\text { Improved } \\
\text { biomarkers: } \\
\text { EF, BP }\end{array}$ \\
\hline $\begin{array}{c}\text { BP cuff, scale, } \\
\text { oxygen } \\
\text { saturation } \\
\text { monitor, } \\
\text { e-Charts }\end{array}$ & $\begin{array}{l}\text { Written } \\
\quad \text { instructions }\end{array}$ & $\begin{array}{l}\text { Analysis of } \\
\text { patients own } \\
\text { perceptions of } \\
\text { problems }\end{array}$ & $\begin{array}{l}\text { Reduced fluid } \\
\text { retention }\end{array}$ \\
\hline NP Assessments & $\begin{array}{l}\text { Acute } \\
\text { Management } \\
\text { Tool }\end{array}$ & $\begin{array}{l}\text { Recognition of } \\
\text { self-care needs }\end{array}$ & Decreased pain \\
\hline $\begin{array}{l}\text { Loopback } \\
\text { Analytics }\end{array}$ & NP visits & $\begin{array}{l}\text { Clinic attendance } \\
\text { with } \\
\text { maintenance of } \\
\text { appointments } \\
\end{array}$ & $\begin{array}{c}\text { Improved decision } \\
\text { making by } \\
\text { increased } \\
\text { adherence } \\
\end{array}$ \\
\hline \multirow[t]{2}{*}{$\begin{array}{l}\text { National } \\
\text { benchmark } \\
\text { data }\end{array}$} & $\begin{array}{l}\text { Face to face } \\
\text { Verbal } \\
\text { instruction }\end{array}$ & $\begin{array}{l}\text { NP transcriptions } \\
\text { of assessment, } \\
\text { medication } \\
\text { review and } \\
\text { care plan }\end{array}$ & $\begin{array}{l}\text { Decreased anxiety } \\
\text { or } \\
\text { hopelessness }\end{array}$ \\
\hline & $\begin{array}{l}\text { Clinic } \\
\text { collaboration } \\
\text { with } \\
\text { community } \\
\text { stakeholders }\end{array}$ & & $\begin{array}{l}\text { Self-evaluation } \\
\text { reflects } \\
\text { perception of } \\
\text { changing } \\
\text { condition and } \\
\text { positive } \\
\text { outlook }\end{array}$ \\
\hline
\end{tabular}

(Logic Model format adapted from Ellerman, Kataoka-Yahiro, \& Wong, 2005). 


\section{APPENDIX G}

\section{THEMATIC ANALYSIS SUMMARY OF QUALITATIVE QUESTION}

\begin{tabular}{|c|c|c|}
\hline Themes & Concepts & Direct quotes from interview participants \\
\hline $\begin{array}{l}1 . \\
\text { Physical } \\
\text { symptoms } \\
\text { and } \\
\text { suffering }\end{array}$ & $\begin{array}{l}\text { Extreme } \\
\text { Fatigue }\end{array}$ & $\begin{array}{l}\text { "I was so tired and weak looks like someone just reached } \\
\text { in and snatched my energy." } \\
\text { "I've been weak ever since I come out of that hospital. I } \\
\text { can't understand why my body weak. I can gets up, I } \\
\text { take my medicine like I should, but I just be weak." } \\
\text { "There seems to be a couple windows to the day when I } \\
\text { have fatigue. Similar to the effect of taking a Benadryl } \\
\text { or something and I just feel like I need to lay down and } \\
\text { take a little } 30 \text { to } 40 \text { minute nap a couple times a day." } \\
\text { "I say no Doctor I don't want a permanent [dialysis] } \\
\text { catheter. I'm going to get better. . .Lord we were } \\
\text { screaming and hollering because I didn't have to go back } \\
\text { over there. It just wear you out to be put to that } \\
\text { machine" } \\
\text { "...Feeling tired, you know and just run down...an } \\
\text { ongoing problem, sleeping." }\end{array}$ \\
\hline & $\begin{array}{l}\text { Shortness of } \\
\text { breath, fluid } \\
\text { retention. }\end{array}$ & $\begin{array}{l}\text { "I've been shortness of breath. I used to could not walk } \\
\text { no length of time." } \\
\text { "The third time. . to the ER. . .the shocking thing was } \\
\text { when I left they weighed me. I had gone down to } 240 \\
\text { some pounds, from } 280 \text { to } 240 \text {. . a miracle really". } \\
\text { "I kept like any man thinking I could do what I want. } \\
\text { One day it just hit me. I couldn't breathe." } \\
\text { "Seemed like I couldn't breathe. It seemed like nothing } \\
\text { couldn't get into me. . .seemed like I couldn't make it." }\end{array}$ \\
\hline $\begin{array}{l}\text { 2. Care } \\
\text { manage- } \\
\text { ment }\end{array}$ & $\begin{array}{l}\text { Stress of } \\
\text { manage- } \\
\text { ment of care }\end{array}$ & $\begin{array}{l}\text { "I had a woman and four kids, then after this she had to } \\
\text { leave. . .I'm four months behind on my house note. . I } \\
\text { was supposed to have a CPAP. But at the time didn't } \\
\text { have insurance and I wasn't able to get it. . .costs like } \\
\$ 1200 . "\end{array}$ \\
\hline
\end{tabular}




\begin{tabular}{|c|c|c|}
\hline & & $\begin{array}{l}\text { "Unemployed, it is frustrating to me and it's difficult } \\
\text { because we like to be doing things around the house and } \\
\text { that's hard to just lay around the house." }\end{array}$ \\
\hline & $\begin{array}{l}\text { Fragmented } \\
\text { healthcare } \\
\text { system and } \\
\text { poor access } \\
\text { to care }\end{array}$ & $\begin{array}{l}\text { "It was a matter of getting access to a physician again } \\
\text { where we could have copies of the problem of } \mathrm{CO}_{2} \text {. We } \\
\text { wound up going to ER with a high } \mathrm{CO}_{2} \text { level above } 36 \text {. } \\
\text { There was no type of follow-up. Then a lack of } \\
\text { information of what was coming out of the hospital about } \\
\text { her problems." } \\
\text { "I used to tell my first year medical students nothing } \\
\text { takes the place of meeting with the patient and the family } \\
\text { and putting your hands on them as far as telling them } \\
\text { what is going on. I think we could have prevented this if } \\
\text { we could have gotten past the gatekeeper to see a } \\
\text { primary care physician. It is frustrating and anger } \\
\text { producing for us." }\end{array}$ \\
\hline & $\begin{array}{l}\text { Caregiver } \\
\text { strain }\end{array}$ & $\begin{array}{l}\text { "I got to do something about my arthritis; I haven't been } \\
\text { able to seek health care. Being a caregiver sometimes } \\
\text { means you don't get a chance to take care of yourself." }\end{array}$ \\
\hline \multirow[t]{2}{*}{$\begin{array}{l}\text { 3. Self- } \\
\text { care } \\
\text { agency or } \\
\text { behaviors }\end{array}$} & $\begin{array}{l}\text { Independ- } \\
\text { ence }\end{array}$ & $\begin{array}{l}\text { "I got some corn, put some salt on it, and the fluid built } \\
\text { up....then that morning could not breathe." } \\
\text { "They always get a wheelchair for me. Dr. say he going } \\
\text { to outlaw that wheelchair." } \\
\text { "If you have your legs down, your feet down } \\
\text { sleepin'...it's gonna draw the fluid up...that's why I'm } \\
\text { tired. I don't sleep good, that's the problem. That's why } \\
\text { I'm getting the fluid. Otherwise my feet wouldn't even } \\
\text { swell probably, right?" }\end{array}$ \\
\hline & Humiliation & $\begin{array}{l}\text { "I ended up with CHF. I gained weight. I couldn't tie } \\
\text { my shoes. I could not wipe myself properly... seemed } \\
\text { like it was so far...It was just a terrible problem and it } \\
\text { had an emotional effect on me." }\end{array}$ \\
\hline $\begin{array}{l}4 . \\
\text { Psycho- } \\
\text { logical } \\
\text { experience }\end{array}$ & $\begin{array}{l}\text { Acknowl- } \\
\text { edgment of } \\
\text { diagnosis }\end{array}$ & $\begin{array}{l}\text { "I kept like any man thinking I could do what I want. } \\
\text { One day it just hit me - I couldn't breathe." } \\
\text { "She had gotten to the point where she was refusing } \\
\text { treatment. But she is getting to the point that she does } \\
\text { accept treatment and does accept following protocols. } \\
\text { [spouse speaking]. We are looking for a place to get a } \\
\text { living will signed." }\end{array}$ \\
\hline
\end{tabular}




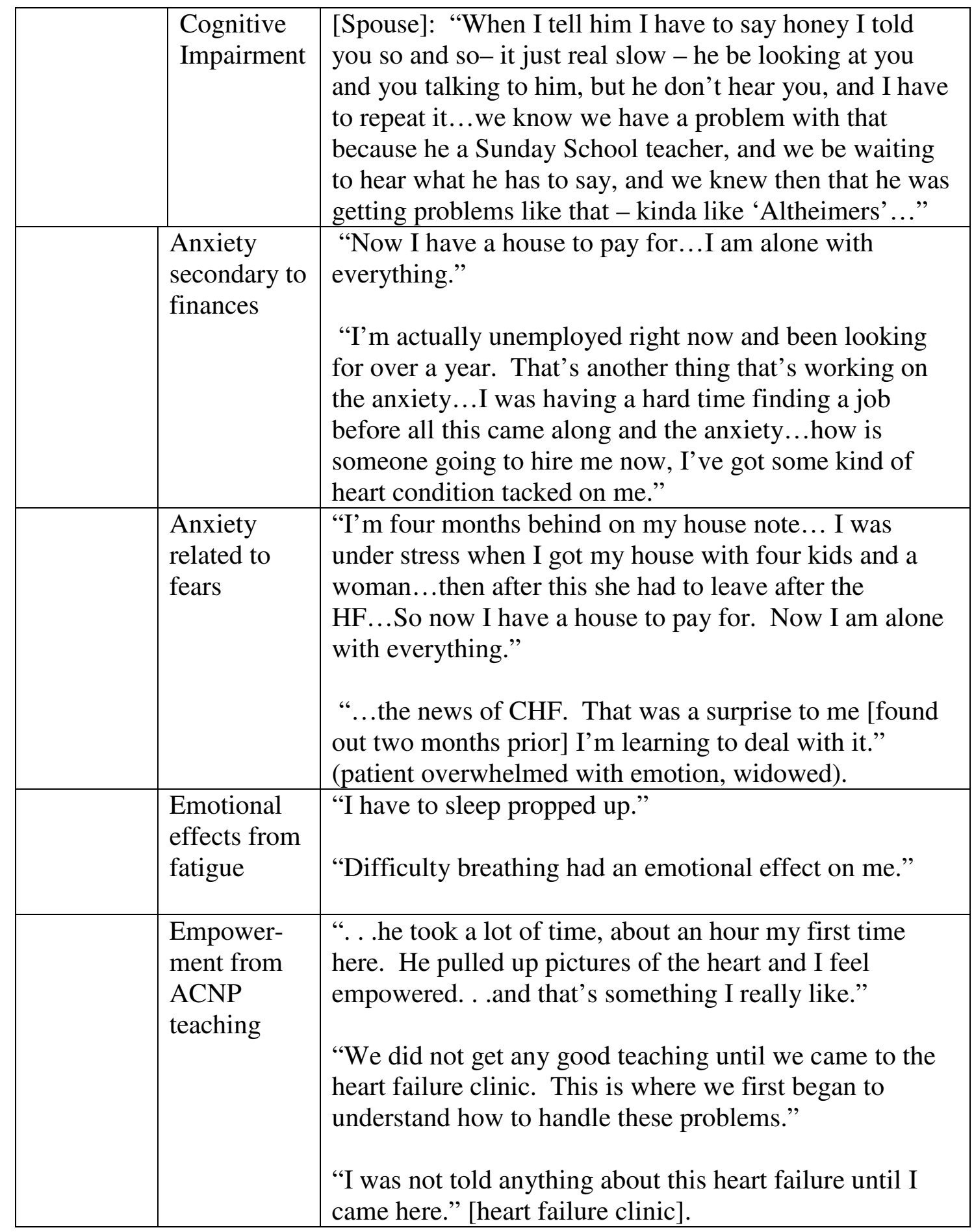




\section{APPENDIX H}

SOCIODEMOGRAPHICS AND BIOMARKERS FOR PROJECT

\begin{tabular}{|c|c|}
\hline Patients $(N=10)$ & $\begin{array}{l}\% \text { of total sample } \\
N=10\end{array}$ \\
\hline $\begin{array}{l}\text { Age } \geq 65 \\
\text { Range } \\
\text { Mean }\end{array}$ & $\begin{array}{l}41-82 \text { years old } \\
56\end{array}$ \\
\hline $\begin{array}{l}\text { Gender } \\
\text { Men } \\
\text { Women }\end{array}$ & $\begin{array}{l}40 \% \\
60 \%\end{array}$ \\
\hline $\begin{array}{l}\text { Marital status } \\
\text { Married } \\
\text { Widowed or single }\end{array}$ & $\begin{array}{l}70 \% \\
30 \%\end{array}$ \\
\hline $\begin{array}{l}\text { Ethnic origin } \\
\text { Caucasian } \\
\text { African American }\end{array}$ & $\begin{array}{l}40 \% \\
60 \%\end{array}$ \\
\hline $\begin{array}{l}\text { HF etiology } \\
\text { Ischemic disease } \\
\text { Valve disease } \\
\text { Chronic pulmonary }\end{array}$ & $\begin{array}{l}70 \% \\
30 \% \\
10 \%\end{array}$ \\
\hline $\begin{array}{l}\text { Left ventricular ejection fraction } \% \\
\quad 15-29 \\
30-44 \\
45-64\end{array}$ & $\begin{array}{l}40 \% \\
0 \\
60 \%\end{array}$ \\
\hline $\begin{array}{l}\text { New York Heart Association Stage } \\
\text { Class III } \\
\text { Class IV }\end{array}$ & $\begin{array}{l}80 \% \\
20 \%\end{array}$ \\
\hline $\begin{array}{l}\text { Systolic BP } \\
\qquad 110 \mathrm{mmHg} \\
120-139 \mathrm{mmHg} \\
140-159 \mathrm{mmHg}\end{array}$ & $\begin{array}{l}20 \% \\
50 \% \\
30 \%\end{array}$ \\
\hline
\end{tabular}

Note. Systolic blood pressure: normal systolic < $120 \mathrm{mmHg}$, prehypertension 120-139 mmHg, hypertension 140-159 mmHg (defined by AHA, 2012). 


\section{REFERENCES}

ACC/AHA. (2011). Heart failure stages and functional classifications. Retrieved from Emory Healthcare: http://www.emoryhealthcare.org/heart-failure/learnabout-heart-failure/stages-classification.html

AHA. (2011). Get with the guidelines heart failure. Retrieved from Outcome: www.outcome.com/qi-ahagwtg.htm

AACN. (2006). Retrieved from the Essentials of Doctoral Education for Advanced Nursing Practice: http://www.aacn.nche.edu/publications/position/DNP Essentials.pdf

AHA. (2012). Understanding Blood Pressure Readings. Retrieved from American Heart Association: http://www.heart.org/HEARTORG/Conditions/HighBlood Pressure/AboutHighBloodPressure/Understanding-Blood-PressureReadings_UCM_301764_Article.jsp

Anfara, V. A., \& Mertz, N. T. (2006). Theoretical frameworks in qualitative research. Thousand Oaks, CA: Sage.

Annema, C., Luttik, M., \& Jaarsma, T. (2009). Reasons for readmission in heart failure: Perspectives of patients, caregivers, cardiologists, and heart failure nurses. Heart \& Lung, 38(5), 427-434.

Aranda, J. M., Johnson, J. W., \& Conti, J. B. (2009). Current trends in heart failure readmission rates: Analysis of Medicare data. Clinical Cardiology Journal, 32(1), 47-52. doi:10.1002/clc.20453

Aspinal, F., Hughes, R., Higginson, I., Chidgey, J., Drescher, U., \& Thompson, M. (2011). A user's guide to the palliative care outcome scale. Retrieved from POS: http://pos-pal.org/index.php 
Balaban, R. B., Weissman, J. S., Samuel, P. A., \& Woolhandler, S. (2008). Redefining and redesigning hospital discharge to enhance patient care: A randomized controlled study. Journal of General Internal Medicine, 23(8), 1228-1233 doi:10.1007/s11606-008-0618-9

Bandura, A. (1977). Social learning theory. Englewood Cliffs, NJ: Prentice-Hall. Baumgartner, H., Bonhoeffer, P., Deanfield, J. E., DeGroot, N. M. F., de Haan, F., Deanfield, J. E., ... Walma, E. (2012). Grown-up congenital heart disease (management of). Retrieved from European Society of Cardiology: http:// www.escardio.org/guidelines-surveys/esc-uidelines/GuidelinesDocuments /guidelines-GUCH-FT.pdf

Bausewein, C., Daveson, B., Benalia, H., Simon, S. T., \& Higginson, I. U. (2012). Outcome measurement in palliative care: The essentials. Retrieved from King's College London Cicely Saunders Institute: http://www.csi.kcl.ac.uk/pos.html Bausewein, C., Grice, C. L., Simon, S. T., \& Higginson, I. J. (2011). The use of two common palliative outcome measures in clinical care and research: A systematic review of POS and STAS. Palliative Medicine, 25(4), 304-313. doi:10.1177/0269216310395984

Bogaev, R. C. (2010). Cost considerations in the treatment of heart failure. 18th Annual Texas Heart Institute Summit, Heart Failure in the Next Decade: The Impact of Novel Therapies on Current Treatment Strategies. Houston, TX: Texas Heart Institute.

Bonow, R. O., Bennett, S., Casey, D. E. Jr, Ganiats, T. G., Hlatky, M. A., Konstam, M. A., ... Sertus, J. A. (2005). ACC/AHA clinical performance measures for adults with chronic heart failure: A report of the ACC/AHA task force on 
performance measures (writing committee to develop heart failure clinical performance measures) endorsed by the HF Society of America. Journal of the Americal College of Cardiology, 46(6), 1144-1178. doi:10.1016/j.jacc.2005. 07.012

Boren, S. A., Wakefield, B. J., Gunlock, T. L., \& Wakefield, D. S. (2009). Heart failure self-management education: A systematic review of the evidence. International Journal of Evidence Based Health, 7, 159-168. doi:10.1111/j.1744-1609.2009.00134.x

Boutwell, A., \& Hwu, S. (2009). Effective interventions to reduce rehospitalizations: A survey of the published evidence. Cambridge, MA: Institute for Healthcare Improvement.

Boutwell, A., Griffin, F., Hwu, S., \& Shannon, D. (2009). Effective interventions to reduce rehospitalizations: A compendium of 15 promising interventions. Cambridge, MA: Institute for Healthcare Improvement.

Burns, N., \& Grove, S. K. (2009). The practice of nursing research: Appraisal, synthesis, and generation of evidence. St. Louis, MO: Saunders Elsevier.

Butts, J. (2011). Philosophies and theories for advanced nursing practice. Sudbury, MA: Jones \& Bartlett.

Butts, J. B., Rich, K. L., \& Fawcett, J. (2012). The future of nursing: How important is discipline-specific knowledge? A conversation with Jacqualine Fawcett. Nursing Science Quarterly, 25(2), 151-154. doi:10.1177/0894318412437955

Carver, C. S., Scheier, M. F., \& Weintraub, J. K. (1989). Assessing coping strategies: A theoretically based approach. Journal of Personality and Social Psychology, 56(2), 267-283. 
Centers for Medicare and Medicaid Services. (2008a). The Medicare recovery audit contractor (RAC) program: An evaluation of the 3-year demonstration. Retrieved from cms.hhs.gov: http://www.cms.hhs.gov/rac/downloads/rac\% 20evaluation\%20report.pdf

Centers for Medicare and Medicaid Services. (2008b). qualitynet.org. Retrieved from CMS 30-Day Heart Failure Readmission Measure National Dry Run Summary Report: www.qualitynet.org/dcs/BlobServer?blobkey=id\&blobnocache= true \&blobwhere $=1228861728346 \&$ blobheader=multipart/octet-stream $\&$ blobheadername1=Content-Disposition\&blobheadervalue $1=$ attachment;filename =HF_RdmDryRunSumRept121808,0.pdf\&blobcol=urldata\&blobtable=Mung Centers for Medicare and Medicaid Services. (2010a). Heart failure (HF): Hospital 30-day, all-cause, risk-standardized readmission rate (RSRR) following HF hospitalization. Retrieved from NQMC National Quality Measures Clearinghouse: http://www.qualitymeasures.ahrq.gov/about/inclusioncriteria.aspx

Centers for Medicare and Medicaid Services. (2010b). Medicare hospital quality chartbook 2010 performance report on outcomes measures for acute myocardial infarction, heart failure, and pneumonia. Retrieved from cms.hhs.gov: http://www.cms.hhs.gov/HospitalQualityInits/... /HospitalChartBook.pdf Centers for Medicare and Medicaid Services. (2012, April 24). Readmissions Reduction Program. Retrieved from CMS.gov: http://cms.gov/Medicare/Medicare-Fee-forService-Payment/AcuteInpatientPPS/Readmissions-Reduction-Program.html/ 
Chan, D. C., Heidenreich, P. A., Weinstein, M. C., \& Fonarow, G. C. (2008). Heart failure disease management programs: A cost-effectiveness analysis. American Heart Journal, 155, 332-338. doi:10.1016/j.ahj.2007.10.001

Chism, L. (2010). The doctor of nursing practice. Sudbury, MA: Jones and Bartlett.

Coleman, E. A., Parry, C., Chalmers, S., \& Min, S. (2006). The care transitions intervention. Archives of Internal Medicine, 166, 1822-1828. clinicaltrials.gov Identifier: NCT00244491.

Collins, S. P., Shauer, D. P., Gupta, A., Brunner, H., Storrow, A. B., \& Eckman, M. H. (2009). Cost-effectiveness analysis of ED decision making in patients with nonhigh-risk heart failure. American Journal of Emergency Medicine 27, 293-302. doi:10.1016/j.ajem.2008.02.025

De Jong, M. M. J., Moser, D. K., \& Chung, M. L. (2005). Predictors of health status for heart failure patients. Progress in Cardiovascular Nursing, 155-162.

Dedhia, P., Kravet, S., Bulger, J., Hinson, T., Sridharan, A., Kolodner, K., . . Howell, E. (2009). A quality improvement intervention to facilitate the transition of older adults from three hospitals back to their homes. Journal of American Geriatric Society, 57, 1540-1546. doi:10.1111/j.1532-5415.2009.02430.x

Delgado-Passler, P., \& McCaffrey, R. (2006). The influences of postdischarge management by nurse practitioners on hospital readmission for heart failure. Journal of the American Academy of Nurse Practitioners, 18, 154-160. doi:10.1111/j.1745-7599.2006.00113.x

Dunham-Taylor, J., \& Pinczuk, J. Z. (2010). Financial management for nurse managers: Merging the heart with the dollar. Sudbury, MA: Jones and Bartlett. 
Ellerman, C. R., Kataoka-Yahiro, M. R., \& Wong, L. C. (2005). Logic models used to enhance critical thinking. Journal of Nursing Education, 220-227.

Fawcett, J. (2008). The added value of nursing conceptual model-based research. Journal of Advanced Nursing, 61(6), 583.

Fineout-Overholt, E., Melnyk, B. M., \& Schultz, A. (2005). Transforming health care from the inside out: Advancing evidence-based practice in the 21st century. Journal of Professional Nursing, 21(6), 335-344.

Fonarow, G. C., Adams, K. F., Abraham, W. T., Yancy, C. W., \& Boscardin, W. J. (2005). Risk stratification for in-hospital mortality in acutely decompensated heart failure. Journal of American Medical Association, 293(5), 572-580.

Forrest General Hospital. (2011). Forrest General Hospital Vision and Mission. Retrieved from ForrestGeneralHospital.com: http://www.forrestgeneral. com/body.cfm?id=52

Glaser, B. G. \& Strauss, A. L. (2009). The discovery of grounded theory: Strategies for qualitative research. Piscataway, NJ: Aldine Transaction, Division of Transaction Publishers.

Greenhalgh, J., Long, A. F., Brettle, A. J., \& Grant, M. J. (1998). Reviewing and selecting outcome measures for use in routine practice. Journal of Evaluation in Clinical Practice, 4(4), 339-350.

Greenwald, J. L., Denham, C. R., \& Jack, B. W. (2007). The hospital discharge: A review of a high-risk care transition with highlights of a reengineered discharge process. Journal of Patient Safety, 3, 97-106. 
Health Net Federal Services. (2011). Disease management educational resources. Retrieved from www.hnfs.com: https://www.hnfs.com/content/hnfs/home/tn/ prov/res/prov_wellness/hetoollanding/hetoolheart.html

Hearn, J., \& Higginson, I. J. (1999). Development and validation of a core outcome measure for palliative care: The palliative care outcome scale. Quality in Health Care, 8, 219-227.

Heart Failure Society of America. (2006). Module 4 self-care: Following your treatment plan and dealing with your symptoms the Heart Failure Society. Retrieved from http://www.hfsa.org/pdf/module4.pdf: www.hfsa.org

Hebert, P. L., Sisk, J. E., Wang, J. J., Tuzzio, L., Casabianca, M. S., \& Chassin, M. R. (2008). Cost-effectiveness of nurse-led disease management for heart failure in an ethnically diverse urban community. Annals of Internal Medicine, 149(8), $540-548$.

Heo, S., Lennie, T. A., Okoli, C., \& Moser, D. K. (2009). Quality of life in patients with heart failure: Ask the patients. Heart \& Lung, 100-108. doi:10.1016/j.hrtlng.2008.04.002

HFSA. (2010). The 2010 Heart Failure Society of America comprehensive heart failure practice guideline. Retrieved from 9.14.2010 - 2010 Comprehensive Heart Failure Practice Guideline Web Site On-line: http://www.heartfailureguideline.org

Hines, P. A., Yu, K., \& Randall, M. (2010). Preventing heart failure readmissions: Is your organization prepared? Nursing Economics, 74-86.

Hunt, S. A ., Abraham, W. T., Chin, M. H., Feldman, A. M., Francis, G. S., Ganiats, T. G., Jessup, M., ... Yancey, C. W. (2001). ACC/AHA 2005 guidelines update 
for the diagnosis and management of chronic heart failure in the adult: A report of the American College of Cardiology/American Heart Association Task Force, Practice Guidelines (Writing Committee to Update 2001 Guidelines). Journal of the American College of Cardiology, 38(7), 2101-2113.

Hunt, S. A., Abraham, W. T., Chin, M. H., Feldman, A. M., Francis, G. S., Ganiats, T. G., Jessup, M., . . Yancy, C. W. (2009). 2009 Focused update incorporated into the ACC/AHA 2005 guidelines for the diagnosis and management of heart failure in adults: A report of the American College of Cardiology Foundation/American Heart Association Task Force on Practice Guidelines. Circulation, 119, e391- e479. doi:10.1161/CIRCULATIONAHA.109.192065. Institute of Medicine. (2002). Health professions education: A bridge to quality. Washington, DC: National Academy Press.

Jack, B. W., Chetty, V. I., Anthony, D., Greenwald, J. L., Sanchez, G.M ., Johnson, A. E., . . Culpepper, L. (2009). A reengineered hospital discharge program to decrease hospitalization: A randomized trial. Annals of Internal Medicine, 150, 178-187. ClinicalTrials.gov registration number: NCT00252057.

Jencks, S. F., Williams, M. V., \& Coleman, E. A. (2009). Rehospitalizations among patients in the Medicare Fee-for-Service program. New England Journal of Medicine, 360, 1418-1428. doi:10.1056/NEJMsa0803563

Jeon, Y., Kraus, S. G., Jowsey, T., \& Glasgow, N. J. (2010). The experience of living with chronic heart failure: A narrative review of qualitative studies. BioMed Central Health Services Research, 10(77), 1-9. doi:10.1186/1472-6963-10-77 Jessup, M., Abraham, W. T., Casey, D. E., Feldman, A. M., Francis, G. S., Ganiats, T. G., .. Y Yancey, C. W. (2009). Writing on behalf of the 2005 Guideline Update 
for the Diagnosis and Management HF. 2009 Focused update: ACCF/AHA guidelines for the diagnosis and management of heart failure in adults. Journal of the American College of Cardiology, 53(15), 1343-1382. doi:

10.1161/CIRCULATIONAHA.109.192064

Jovicic, A., Holroyd-Leduc, J. M., \& Straus, S. E. (2006). Effects of self-management intervention on health outcomes of patients with heart failure: A systematic review of randomized controlled trials. Biomed Central Cardiovascular Disorders, 6, 43.

Joynt, K. E., Orav, E. J., \& Jha, A. K. (2011). The association between hospital volume and processes, outcomes, and costs of care for congestive heart failure. Annals of Internal Medicine, 154, 94-102.

Klersy, C. K., De Silvestri, A., Gabutti, M. A., Regoli, F., \& Auricchio, A. (2009). A meta-analysis of remote monitoring of heart failure patients. Journal of the American College of Cardiology, 54(18), 1683-1694. doi:10.1016/j.jacc.2009 .08 .017

Koelling, T. M., Johnson, M. L., Cody, R. J., \& Aaronson, K. D. (2005). Discharge education improves clinical outcomes in patients with chronic heart failure. Circulation, 111(2), 179-185.

Konick-McMahan, J., Bixby, B., \& McKenna, C. (2003). Heart failure in older adults: Providing nursing care to improve outcomes. Journal of Gerontological Nursing, 35-41.

Krumholz, H. M., Amatruda, J., Smith, G. L., Mattera, J. A., Roumanis, S. A., Radford, M. J., \& Crombie, P. (2002). Randomized trial of an education and support 
intervention to prevent readmission of patients with heart failure. Journal of the American College of Cardiology, 39(1), 83-89.

Krumholz, H. M., Merrill, A. R., Schone, E. M., Schreiner, G. C., Chen, J., Bradley, E. H., . . Drye, E. E. (2009). Patterns of hospital performance in acute myocardial infarction and heart failure 30-day mortality and readmission. Circulation Cardiovascular Quality and Outcomes American Heart Association Journal, 407-413. doi:10.1161/CIRCOUTCOMES.109.883256

Lazarus, R. S., DeLongis, A., Folkman, S., \& Gruen, R. (1985). Stress and adaptational outcomes. American Psychologist, 40(7), 770-779.

Lee, C. S., Moser, D. K., Lennie, T. A., \& Riegel, B. (2009). Event-free survival in adults with heart failure who engage in self-care management. Heart \& Lung, 40(1), 12-20. doi:10.1016/j.hrtlng.2009.12.003

Lee, R. H. (2009). Economics for healthcare managers. Chicago, IL: Health Administration Press.

Lennie, T. A., Worrall-Carter, L., Hammish, M., Odom-Forran, J., Roser, L. P., Smith, C. S., . . Moser, D. K. (2008). Relationship of heart failure patients' knowledge of perceived barriers and attitudes regarding low-sodium diet recommendations to adherence. Progress in Cardiovascular Nursing, 6-11.

Liao, L., Allen, L. A., \& Whellan, D. J. (2008). Economic burden of heart failure in the elderly. Pharmacoeconomics, 26(6), 447-462.

Lindenfeld, J., Albert, N. M., Boehmer, J. P., Collins, S. P., Ezekowitz, J. A., Givertz, M. M., Clapholz, M., .. . Walsh, M. N. (2010). [Title]. Retrieved from http://www.heartfailureguideline.org/8_disease_management_advance_directive s_end-of-life_care/24. 
Lloyd-Jones, D., Adams, R., Carnethon, M., DeSimone, G., Ferguson, T. B., Flegal, K., ... Hong, Y. (2008). Heart disease and stroke statistics-2009 Update: A report from the American Heart Association Statistics Committee and Stroke Statistics Subcommittee. Journal of the American Heart Association, e2-e159. doi:10.1161/CIRCULATIONAHA.108.191261

Loopback Analytics. (2011). Loopback analytics readmission reduction. Dashboard Report. Dallas, TX: Loopbacks Analytics.

Lorenz, K. A., Lynn, J., Dy, S. M., Shugarman, L. R., Wilkinson, A., Mularksi, R. S., ... Shekelle, M. D. (2008). Evidence for improving palliative care at the end of life: A systematic review. Annals of Internal Medicine, 148, 147-159.

Majumdar, S. R., McAlister, F. A., \& Furberg, C. D. (2004). From knowledge to practice in chronic cardiovascular disease: A long and winding road. Journal of the American College of Cardiology, 43(10), 1738-1742. doi:10.1016/j. jacc.2003.12.043

McAlister, F. A., Stewart, S., Ferrua, S., \& McMurray, J. J. V. (2004). Multidisciplinary strategies for the management of heart failure patients at high risk for admission: A systematic review of randomized trials. Journal of the American College of Cardiology, 44(4), 810-819. doi:10.1016/j.jacc.2004. 05.055

Medical Dictionary. (2012, June). Retrieved June 14, 2012, from MedicineNet.com: http://www.medicinenet.com

Moser, D. K., \& Watkins, J. F. (2008). Conceptualizing self-care in heart failure: A life course model of patient characteristics. Journal of Cardiovascular, 23(3), 205-218. 
Moser, D. K., Frazier, S. K., Worrall-Carter, L., Biddle, M. J., Chung, M. L., Lee, K. S., \& Lennie, T. A. (2011). Symptom variability, not severity, predicts rehospitalization and mortality in patients with heart failure. European Journal of Cardiovascular Nursing, 10(124), 124-130. doi:10.1016/j.ejcnurse. 2010.05.006

Muth, C., Gensichen, J., Beyer, M., Hutchinson, A., \& Gerlach, M. (2009). The systematic guideline review: Method, rationale, and test on chronic heart failure. BioMed Central Health Services Research, 9(74). doi:10.1186/1472-6963-9-74

Naylor, M. D., Brooten, D. A., Campbell, R. L., Maislin, G., McCauley, K. M., \& Schwartz, J. S. (2004). Transitional care of older adults hospitalized with heart failure: A randomized, controlled trial. Journal of American Geriatric Society, $52,675-684$.

Newhouse, R. P., Dearholt, S. L., Poe, S. S., Pugh, L. C., \& White, K. M. (2007). Johns Hopkins nursing evidence-based practice model and guidelines. Indianapolis, IN: Sigma Theta Tau International.

O'Reilly, K. (2011, February 7). Reducing readmissions: How 3 hospitals found success. Retrieved from American Medical News: http://www.amednews.com

Paul, S. (2008). Hospital discharge education for patients with heart failure: What really works and what is the evidence? Critical Care Nurse, 28(2), 66-82.

Phillips, C. O., Wright, S. M., Kern, D. E., Singa, R. M., Shepperd, S., \& Rubin, H. R. (2004). Comprehensive discharge planning with postdischarge support for older patients with congestive heart failure-a meta-analysis. Journal of American Medical Association, 291, 1358-1367. 
Polit, D. F., \& Beck, C. T. (2008). Nursing research: Generating and assessing evidence for nursing practice. Philadelphia, PA: Lippincott Williams \& Wilkins.

Rice, V. (2000). Handbook of stress, coping, and health: Implications for nursing research, theory, and practice. Thousand Oaks, CA: Sage.

Rich, M. W., \& Nease, R. F. (1999). Cost-effective analysis in clinical practice: The case of heart failure. Archives of Internal Medicine, 159, 1690-1700.

Riegel, B., Lee, C. S., \& Sochalski, J. (2010). Developing an instrument to measure heart failure disease management program intensity and complexity. Circulation Cardiovascular Quality Outcomes, 324-330. doi:10.1161/CIRCOUTCOMES.109.877324

Rodriguez, K. L., Appelt, C. J., Switzer, G. E., Sonel, A .F., \& Arnold, R. M. (2008). “They diagnosed bad heart": A qualitative exploration of patients' knowledge about and experiences with heart failure. Heart \& Lung, 257-265. doi:10.1016/j.hrtlng.2007.09.001

Ross, J. S., Chen, J., Lin, Z., Bueno, H., Curtis, J. P., Keenan, P. S., . . Krumholz, H. M. (2010). National trends in readmission rates after heart failure hospitalization. Circulation Heart Failure, 3, 97-103. doi:

\subsection{1/CIRCHEARTFAILURE.109.885210}

Shepperd, S., McClaran, J., Phillips C. O., Lannin, N. A., Clemson, L. M., McCluskey, A., ... Barras, A. L. (2010). Discharge planning from hospital to home (Review): The Cochrane Collaboration. Cochrane Database of Systematic Reviews, 2010(1), 1-75. doi:10.1002/14651858.CD000313.pub3 
Sochalski, J., Jaarsma, T., Krumholz, A., McMurray, J. J. V., Naylor, M. D., Rich, M. W. . . Stewart, S. (2009). What works in chronic care management: The case of heart failure. Health Affairs, 28(1), 179-189. doi 10.1377/hlthaff.28.1.179

Statistics, U. D. (2010, April 12). Consumer price index. Retrieved from Measuring Price Change for Medical Care in the CPI: http://www.bls.gov/cpi/cpifact4.htm

Stillwell, S. B., Fineout-Overholt, E., Melnyk, B. M., \& Williamson, K. M. (2010a). Asking the clinical question: A key step in evidence-based practice. American Journal of Nursing, 110(3), 58-61. doi 10.1097/01.NAJ.0000368959.11129.79

Stillwell, S. B., Fineout-Overholt, E., Melnyk, B. M., \& Williamson, K. (2010b). Evidence-based practice step by step: Searching for the evidence. American Journal of Nursing, 110(5), 41-47. doi:10.1097/01.NAJ.0000372071.24134.7e

Stone, J., \& Hoffman, G. J. (2011, September 21). Medicare hospital readmissions: Issues, policy options and PPACA. Retrieved from hospitalmedicine.org: http://www.hospitalmedicine.org/AM/pdf/advocacy/CRS_Readmissions_Report .pdf

Taylor, M. (2010, January). Shutting the door on readmissions. Retrieved from Hospitals \& Health Networks: www.hhnmag.com

Terry, A. (2012). Clinical research for the doctor of nursing practice. Sudbury, MA: Jones \& Bartlett.

Titler, M. (2007). Translating research into practice. American Journal of Nursing, 107(6), 1-33.

USDHHS. (2010). National healthcare quality report, 2010. Retrieved from AHRQ Agency for Healthcare Research: http://www.ahrq.gov/qual/nhqr10/Chap2a.htm 
USDHHS. (2011, April 11). Hospital compare. Retrieved from Department of Health and Human Services hhs.gov: www.hospitalcompare.hhs.gov/Hospital/Search

Wang, G., Zhang, Z., Ayala, C., Wall, H. K., \& Fang, J. (2010). Costs of heart failurerelated hospitalizations in patients aged 18 to 64 years. American Journal of Managed Care, 16(10), 769-776.

Waterworth, S., \& Jorgensen, D. (2010). It's not just about heart failure--voices of older people in transition to dependence and death. Health and Social Care in the Community, 199-207. doi:10.1111/j.1365-2524.2009.00892.x

White, K. M., \& Dudley-Brown, S. (2012). Translation of evidence into nursing and health care practice. New York, NY: Springer.

Wong, E. L.Y., Cheung, A.W. L., Leung, M. C. M., Yam, C. H. K., Chan, F. W. K., \& Wong, F. Y. Y. (2011). Unplanned readmission rates, length of hospital stay, mortality, and medical costs of ten common medical conditions: A retrospective analysis of Hong Kong hospital data. BioMed Central Health Services Research, 11(149), 1-8. doi:10.1186/1472-6963-11-149

World Health Organization. (2012). Definition of health. Retrieved from About WHO: https://apps.who.int/aboutwho/en/definition.html

Yu, D. S. F., Lee, D. T. F., Kwong, A. N. T., Thompson, D. R., \& Woo, J. (2008). Living with chronic heart failure: A review of qualitative studies of older people. Journal of Advanced Nursing, 61(5), 474-483. doi:10.1111/j.13652648.2007.04553.x

Zaccagnini, M. E., \& White, K. W. (2011). The doctor of nursing practice. Sadbury, MA: Jones \& Bartlett. 